\title{
RENATO OHARA
}

\section{Caracterização do perfil assistencial dos pacientes adultos} de um pronto-socorro

\author{
Dissertação apresentada à Escola de \\ Enfermagem de Ribe irão Preto da \\ Universidade de São Paulo - EERP/USP \\ para obtenção do Título de Mestre em \\ Enfermagem \\ Área de Concentração: Enfermagem \\ Fundamental \\ Linha de pesquisa: Dinâmica da \\ organização dos serviços de s aúde e de \\ enfermagem \\ Orientadora: Profa. Dra . Márcia Regina \\ Antonietto da Costa Melo
}

\section{Ribeirão Preto}


Autorizo a reproduç ão total ou parcial deste trabalho, por qualquer meio convencional ou eletrônico, para fins de estudo e pesquis a, desde que citada a fonte.

Ribeirão Preto-SP, de Junho de 2009

\section{RENATO OHARA}

Ficha Catalográfica

Ohara, Renato. Caracterização do perfil assistencial dos pacientes adultos de um pronto-socorro. / Renato Ohara - Ribeirão Preto, 2009.

$72 \mathrm{p}$.

Dissertação de Mestrado - Escola de Enfermagem de Ribeirão Preto da Universidade de São Paulo.

Orientadora: Profa Dra Márcia Regina Antonietto da Costa Melo

Descritores: Pronto-socorro , Dimensionamento de pessoal, Classificação de pacientes, Equipe de enfermagem. 
Nome: RENATO OHARA

Título: Caracterização do perfil assist encial dos pacientes adultos de um prontosocorro

Dissertação apresentada à Escola de Enfermagem de Ribeirão Preto da Univ ersidade de São Paulo EERP/USP para obtenção do Tí tulo de Mestre em Enfermagem

Área de Concentração: Programa de Enfermagem Fundamental

Linha de pesquisa: Dinâmica da organizaç ão dos serviços de saúde e de enfermagem

Aprovado em :

\section{Banca Examinadora}

Prof $^{a}$ Dra $^{a}$ Márcia Regina Antonietto da Costa Melo

Instituição: EERP-USP

Julgamento:

Assinatura:

Prof $^{\circ} \mathrm{Dr}^{\circ}$

Instituição:

Julgamento:

Assinatura:

Prof $^{\circ} \mathrm{Dr}^{\circ}$

Instituição:

Julgamento:

Assinatura:

Prof $^{\circ} \mathrm{Dr}^{\circ}$

Instituição:

Julgamento:

Assinatura: 
Dedicatória

A Deus

Aos meus pais pela formação e exemplo

Aos meus filhos Lucas, Vitória e João Vítor que me ensinam todos os dias a ser uma pessoa melhor

À Elisabete, exemplo de persistência, acima de tudo companheira, sempre acreditou que era possível quando eu mesmo não acreditei que seria

A todas as pessoas que em momentos de fragilidade e vulnerabilidade se disponibilizaram a colaborar neste estudo 
Agradecimentos

À Profa Dra Márcia Regina Antonietto da Costa Melo pela orientação deste trabalho mas principalmente pela paciência e persistência

À Professoras Doutoras Ana Maria Laus e Janete Rodrigues da Silva Nakao pelas valiosas sugestões no exame de qualificação

À Associação Santa Marcelina que não agrega serviços mas exemplos de como é possível fazer melhor

Ao Conselho Nacional de Desenvolvimento Científico e Tecnológico - CNPq pelo auxílio no desenvolvimento deste trabalho

À Faculdade Santa Marcelina pela oportunidade e pelo crédito

Às Enfermeiras Daniela de Cássia Teixeira da Silva e Michelle Januário Simões pela inestimável colaboração na coleta dos dados

À Profa Dra Káthia de Carvalho Cunha por ter acreditado que era possível e pelo incentivo

Todos os agradecimentos registrados podem não ser suficientes e justos a todos que colaboraram e possibilitaram a realização deste trabalho, de qualquer forma muito obrigado! 
OHARA, R. Caracterização do perfil assistencial dos pacientes adultos de um pronto-socorro. 2009. $71 \mathrm{f}$. Dissertação (mestrado) - Escola de Enfermagem de Ribeirão Preto, Universidade de São Paulo, 2009.

O pronto socorro é uma unidade do hospita I destinada à assistência a pacientes externos com ou sem risco de morte, que necessitam de atendimento imediato, cujo funcionamento se dá nas 24 horas do dia sendo fundamental a determi nação do número necessário de profissionais de en fermagem para prestar assistência com qualidade satisfatória, pois a falta de prof issionais de enfermagem com diferentes níveis de formação e a sobrecarga de trabal ho aumentam o risc o de ocorrência de falhas com prejuízo da qualidade na assist ência ao paciente. Os instrumentos de classificação de pacie ntes são u tilizados $p$ ela enfermagem em qualq uer u nidade assistencial e estabelecem as c aracterísticas da população assis tida de acordo com a necessidade de cuidados requerida, sendo indispensável para a determinação das necessidades de pessoal e aloc ação quantitativa e qualitativa dos mesmos. Com o objetivo de caracterizar o perfil ass istencial dos pacientes adultos dur ante a internação no pronto-socorro como um dos subsídios para o dimensionamento do pessoal de enfermagem desenv olveu-se um a pesquisa exploratória no método do estudo de caso, em um pronto-socorro, clín ico e cirúrgico, de um hospital geral, público est adual que possui 24 leitos de observação e dez leitos na unidade de atendimento de emer gências, localizado no extremo leste do município de São Paulo que trabalha com demanda espontânea do us uário. Os sujeitos da pesquisa foram os pacientes adultos internados na unidade de emergência e nas salas de observação durante o mês de j aneiro de 2009, os dados foram coletados por meio da aplicaç ão do instrumento de classificaç ão de pacientes de F ugulin (2002) que avalia nove áreas de cuidado (Estado mental, Oxigenação, Sinais Vitais, Motilidade, Deambulação, Alimentação, Cuidado Cor poral, Eliminação e T erapêutica). Foram realizadas 1.228 av aliações, sendo ver ificados 91 pacientes na categoria de cuidados intensivos, 75 na categoria de cuidados semi-intensivos, $245 \mathrm{com}$ alta dependência para as sistência de enferm agem, 272 com complexidade as sistencial intermediária e 545 c om a míni ma. Houve a constatação de muitos pacientes da psiquiatria internados no pronto-socorro a espera de vagas para internação na unidade especializada requer endo da equipe de enfermagem uma assistência diferenciada para a manutenção da integridade física desses pacientes. Verificou-se por meio do número médio mensal de at endimentos realizad os que a maioria dos usuários do pronto-socorro não necessitav a de internação mas foram atraídos par a esse serviço em busca de consultas de rotina acabando por sobrecarregar a equip e multiprofissional que atua nessa unidade que apresentou uma taxa de oc upação média acima da previsão dos leitos ofic iais dis poníveis tornando a planta física inadequada para pac ientes e pr ofissionais devido às inte rnações em macas pelos corredores, reflexo da falta de um serviço de regulação.

Palavras c have: Pronto-socorro, Dim ensionamento de pessoal, Class ificação de pacientes, Equipe de enfermagem. 
OHARA, R. Characterization of the care profile of adult patients of an emergency medical service. 2009. $71 \mathrm{f}$. Dissertação (mestrado) - Escola de Enfermagem de Ribeirão Preto, Universidade de São Paulo, 2009.

The emergency medical service is the hospi tal ward designated to outpatient care with or wit hout death risk for those who need immediate care, whose attendance is 24 hours a day, being essential the determi nation of a required number of nursing professionals for delivering satisfactory quality care, since the lack of nursing professionals with different levels of background and work overload increase the risk of errors, impairing the quality of pati ent care. The instruments of patient classification are used by nursing in any care ward and set up the characteristics of the population assisted, according to $t$ he need of care required, being vital for determining the personnel needs and its quantitative and qualit ative alloc ation. Aiming to characterize the adult patient ca re profile throughout the admiss ion at the emergency medical service, as a support fo $r$ nursing personnel dim ensioning, it was developed an exploratory research in a study of case method, at a clinic and surgical emergency room of a general, public state hospital that holds 24 observation beds and 10 beds at the emergency attendance ward, located at the extreme east of São Paulo city and which works wit $h$ spontan eous dem and of users. The subjects of research were adult patients admitted at the emergency ward and the observation rooms throughout the month of January, 2009. Dat a was collected through the application of an instrument of patient classificat ion by Fugulin (2002), which evaluates nine care areas (Mental Status, Oxygenation, Vital Signs, Motility, walking, Feeding, Body Care, Elimination and T herapeutics). It was made 1228 evaluations, in whic $h 91$ patients in the intensive care category were verified, 75 in the semiintensive care, 245 with high dependence of nursing care, 272 with intermediate care complexity and 545 with minim al one. There was the evidence of many $p$ sychiatric patients admitted in the emer gency room waiting for a vacancy in the specialized ward requiring from the nursing s taff special care for keeping the physical integrity of those patients. It was verified by the $m$ onthly av erage number of attendance that most emergency room users di dn't need admissi on, but they were attracted to this service in search for routine appointments, leading to overload the multi-professional team that works in this ward, which presented an average occupancy rate above the prediction of official beds available, making the physical space inadequate for patients and professionals, du e to the admissions in beds spread in corridors, result of lack of service control.

Key words: Emergency medical s ervice, Personnel dimensioning, Patient classification, Nursing staff. 


\section{Resumen}

OHARA, R. Caracterización del perfil asistencial de los pacientes adultos de un servicio médico de urgencia. 2009. 71 f. Diss ertação (mestrado) - Escola de Enfermagem de Ribeirão Preto, Universidade de São Paulo, 2009.

El servicio médico de urgencia es una unidad del hos pital destinada a la as istencia de pacientes externos con o sin riesgo de muerte, que neces itan de atendimient $o$ inmediato, cuyo funcionam iento es durante las 24 horas del día siendo fundamental la determinación del númer o necesario de profesional es de enfermería para dar asistencia con calidad satisfactoria, ya que la falta de profesionales de enfermería con diferentes niveles de graduación y la sobrecarga de trabajo aumentan el riesgo de ocurrencia de fallas con prejuicio de la calidad en la asistencia al pac iente. Los instrumentos de clasificac ión de pac ientes son utilizad os por la enfermería en cualquier unidad as istencial y establecen la s características de la poblac ión asistida de acuerdo con la necesidad de cuidados requeridos, siendo indi spensable para la determinación de las necesidades del personal y asignación cuantitativa y cualitativa de los mis mos. Con el objetivo de caracteriz ar el perfil asistenc ial de los pacientes adultos dur ante la internación en el servic io médico de urgenc ia como uno de los subsidios para el dimensionamiento del personal de enf ermería se desenvolvió una investigación exploratoria en el método del estudio de caso, en un servicio médico de urgencia , clínico y de c irugía, de un hospit al general, públic o estatal que pos ee 24 camas de observación y diez cama s en la unidad de atendimiento de emergencias, localizado en el extremo este del municipio de San Pablo que trabaja con demanda espontánea del usuario. Los su jetos de la inv estigación fueron los pacientes adultos internados en la uni dad de emergencia y en las $s$ alas $d$ e observación durante el mes de enero del 2009, los datos fueron recogidos por medio de la aplicación del instrumento de clasific ación de pacientes de Fugulin (2002) que evalúa nueve áreas de cuid ado (Estado mental, Oxige nación, Señales Vitales, Motilidad, Deambulación, Alimentación, Cuidado Corporal, Eliminación y Terapéutica). Fueron realizadas 1.228 evaluaciones, siendo verificados 91 pacientes en la categoría de c uidados intensivos, 75 en la c ategoría de cuidados semiintensivos, 245 con alta dependenc ia par a asistencia de enfermería, 272 con complejidad asistencial intermediaria y 545 con la mínima. Hubo la constatación de que muchos pacientes de psiquiatría inte rnados en el pronto-socorro a espera de lugar para internación en la unida d es pecializada requiriendo del equipo de enfermería una asistencia diferenciada para el mantenimiento de la integridad física de esos pacientes. Se $v$ erificó por medio del número promedio $\mathrm{m}$ ensual de atendimientos realizados que la mayoría de los us uarios del s ervicio médico de urgencia no necesitaban de internación pero f ueron atraídos para ese servicio en busca de consultas de rutina acabando por sobrecargar al equipo multiprofesional que actúa en esa unidad que pr esentó una tasa de oc upación promedio arriba de la previsión de las camas oficiales disponib les convirtiendo la pl anta física inadecuada para pacientes y profesionales debido a la $s$ internaciones en camillas por los pasillos, reflejo de la falta de un servicio de reglamentación.

Palabras clave: Serv icio médico de urgencia , Dimensionamiento de personal, Clasificación de pacientes, Equipo de enfermería. 


\section{Lista de tabelas}

Tabela 1. Caracterização da Unidade de Pr onto Socorro em relação ao número de leitos e do número de atendimentos realizados no ano de 2008. .32

Tabela 2. Caracterização da Unidade de Pronto Socorro em relação ao número total de profissionais de enfermagem para as 24 horas do dia, dist ribuídos em quatro plantões.

Tabela 3. Número total de av aliações dos pacientes adultos e frequência de distribuição quanto ao grau de dependência assistencial no período de 30 dias no Pronto Socorro.

Tabela 4. Número total de avaliações dos pacientes adultos e frequência de distribuição de acordo co $m$ a po ntuação $p$ or grau de dependência no período de 30

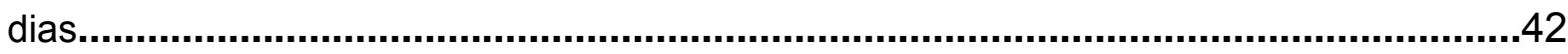

Tabela 5. Número total de avaliações dos pacientes adultos distribuídos por unidade de internação no Pronto Socorro no período de 30 dias.

Tabela 6. Número total de avalia ções dos pacientes adultos e frequência de distribuição quanto ao g rau de dep endência assistencial n o período d e 30 dias $\mathrm{n}$ o Pronto-socorro, de acordo com a Resolução COFEN N 293/2004. 


\section{Lista de figuras}

Figura 1. Distribuição das Coordenadorias de Saúde do Município de São Paulo por

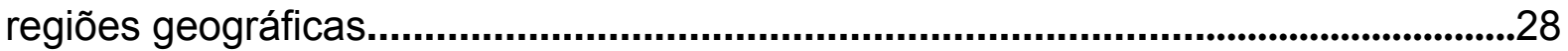

Figura 2. Fluxograma de atendimento dos pacientes adultos do pronto-socorro................32 
SUMÁRIO

1 INTRODUÇÃO

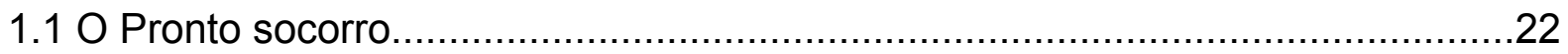

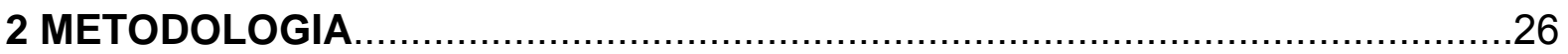

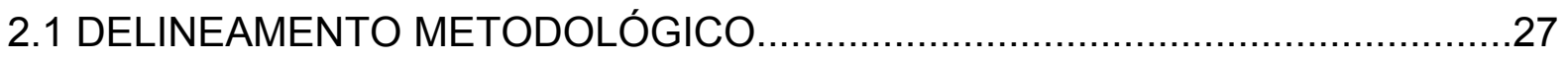

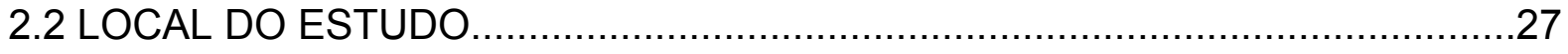

2.2.1 A Organização Social de Saúde Santa Marcelina ..........................................28

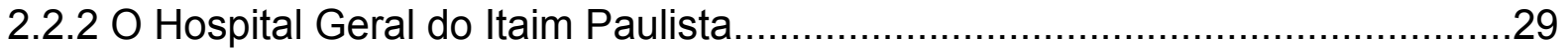

2.2.3 A Unidade de Pronto Socorro do Hospital Geral do Itaim Paulista....................30

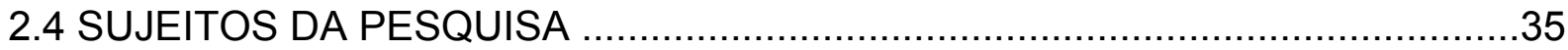

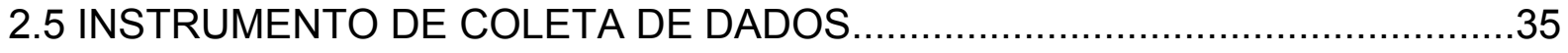

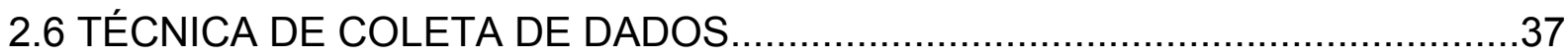

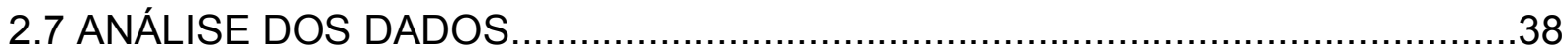

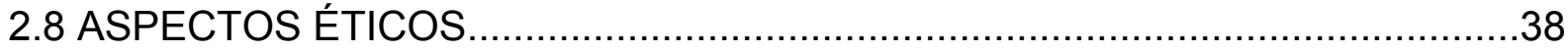

3. APRESENTAÇÃO DOS DADOS E ANÁLISE DOS RESULTADOS .................40

3.1CARACTERIZAÇÃO DO PERFIL ASSISTENCIAL....................................... 41

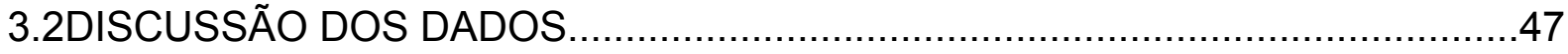

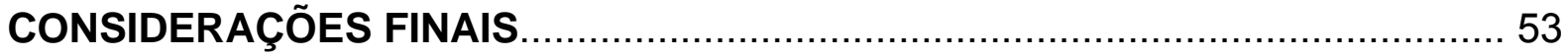

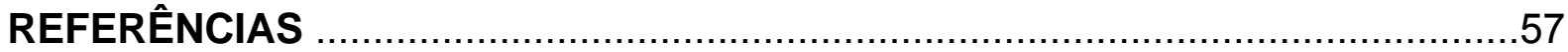

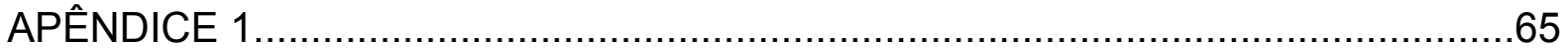

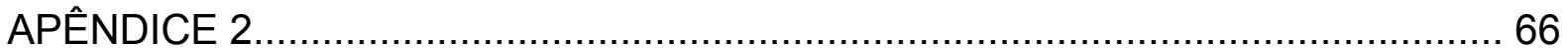

APÊNDICE 3

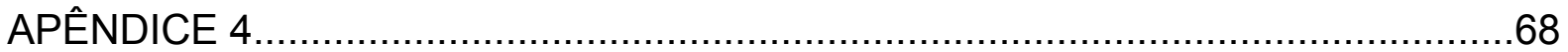

APÊNDICE 5

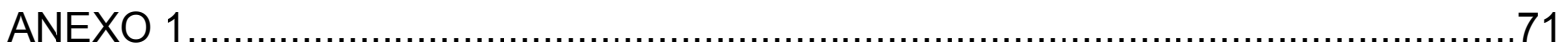


Introdução 


\section{INTRODUÇÃO}

A temática do dimens ionamento de pessoal, das competências requeridas ao enfermeiro para a sua realização, dos par âmetros estabelecidos e principalment e quais variáveis dev eriam ser consideradas para es se cálculo despertaram meu interesse durante a graduação em enferm agem e continuaram sendo foco de atenção, enquanto at uava como enfermeiro em uma unidade de pronto-socorro de um hospital geral no município de São Paulo.

O processo de trabalho no pronto-soco rro era bastante intenso, por ser desenvolvido em uma unidade que func iona de porta aberta e com demanda espontânea em uma região bastante populosa e carente no município de São Paulo.

Nessa época, eram frequentes, por parte dos enfermeiros de todos os turnos de trabalho do pront o-socorro as coloc ações sobre as de dificuldades enfrentadas diariamente no desenvolviment o das atividades com relação às questões: falta de profissionais de enfermagem com diferent es níveis de formação; sobrecarga de trabalho e, consequentemente, aumento no risco de ocorrência de falhas na assistência ao pac iente. A esse propósit o, Veiga (1995), reforça que a constant e pressão gerada pela ansiedade e pelo es tresse pode determinar a ocorrência de iatrogenias por parte da equipe de enfermagem.

Além das questões relativas à quali dade da assist ência de enfermagem prestada aos clientes e da po ssibilidade de incidência de e rros durante essa prática, também era preocupante o número de ausências não previstas, a própria qualidade de vida no trabalho e o grau de satisfaç ão dos profissionais de enfer magem do pronto-socorro.

Em 2003, durante a realização do curso de pós-graduação lato sensu em Gerenciamento de Unidades e Serviços de Enfermagem na Faculdade Santa Marcelina, e depois de uma breve vivênc ia num pronto-socorro de um hospital público municipal da zona leste do município de São Paulo, me aproximei mais da temática devido às discussões com out ros enfermeiros que vivenciavam outras realidades institucionais. 
A constatação, porém, foi de que as difi culdades eram muito semelhantes em termos de falta de subsídios, primei ramente para a determinação do número necessário de profissionais de enfermagem par a prestar assistência com qualidade satisfatória, tanto para os pac ientes quanto para os profi ssionais env olvidos e depois, para a reivindicaç ão e ar gumentação, frente aos adminis tradores, quanto à necessidade de ampliação do quadro laborativo.

Embora o pessoal de enfermagem $r$ epresente o maior contingente nas instituições de saúde, estudos de div ersos autores como Bittar (1997), Picchiai (2000) e Antunes e Costa (2003) demonstram que a questão do seu dimensionamento ade quado ainda é polêmica, princ ipalmente no que se refere à sua adequação enquanto recurso necessário para a assistência preconizada às especificidades e necessidades assistenciais de cada cliente.

Campedelli et al (1988) referem que o pessoal de enfermagem represent a percentual importante quando comparado ao quantit ativo total de profissionais no hospital, em virtude da natureza das ativ idades des envolvidas, pois o serviço de enfermagem tem papel fundamental no atendimento à saúde dos pacientes.

De ac ordo com Madalosso (2000), a enf ermagem atua di retamente com o cliente, por um período bastante $\mathrm{pr}$ olongado e $\mathrm{c}$ om um grande número de intervenções. A iatrogenia relaciona-se à privação do cuidado, à sua imposição ou à prestação insatisfatória de cuidados, de forma que as ações ou omissões causem algum transtorno, dano ou prejuízo ao bem-estar do cliente.

A questão da previsão da necessidade de pessoal para o desenvolviment $\quad 0$ das atividades faz parte de todas as inst ituições, des de a mais simples prestadora de serviços até a mais complexa atividade industrial, não basta dispor de tecnologia de ponta, se ela não for adequadamente utiliz ada por pessoas competentes, com eficácia e eficiência.

De acordo com Chiavenato (2002, p.199),

(...) o planejamento de pessoal é o processo de decisão a respeito dos recursos humanos necessár ios para atingir os objetivos organizacionais, em determinado período de tempo. Trata-se de 
antecipar qual a força de trabalho e os talentos humanos necessários para a realização da ação organizacional futura. (...) Para alcançar todo seu potencial de realizaçõe $s$, a organização precisa ter as pessoas adequadas disponíveis para o trabalho a ser realizado. Em termos práticos, isto significa que todos os gerentes devem estar seguros de que os cargos sob sua responsabilidade estão ocupado $\mathrm{s}$ por pessoas capazes de desempenhá-los adequadamente (...)

Segundo Gaidzinski (1994, p.8),

(...)o dimensionamento de pessoal de enfermagem é a et apa inicial do processo de provimento de pessoal, que tem por finalidade a previsão da quantidade de funcionários por categoria, requerida para suprir as $n$ ecessidades de assistê ncia de en fermagem, direta e indiretamente prestada à clientela.

O dimensionamento do pessoal de enf ermagem deve ser realizado pelo enfermeiro, devendo, de acor do com o Conselho Federa I de Enfermagem (C OFEN, 2004), ser garantida a autonom ia do enfermeiro nas unida des assistenciais, para dimensionar e gerenciar o quadro de prof issionais de enfermagem. Mas, enquant $o$ processo, sofre influência direta de uma série de fatores determinantes relacionados às questões institucionais, principa Imente aquelas que envolvem recursos financeiros, uma vez que a folha de pagamento representa o maior custo dentro das instituições de saúde e os administradores, que habitualmente não são enfermeiros, nem sempre entendem a provisão adequada de pessoal como uma variável fundamental à qualidade da assistência.

Ao longo de anos, o dimensionament o de pessoal de enfermagem tem si do foco, por parte de enfermeiros e administra dores de serviços de saúde, por interferir diretamente na eficácia, na qualidade e no custo da assistência à saúde, uma vez que a equipe de enf ermagem responde pela maioria do quadro de pessoal das instituições. (GAIDZINSKI, FUGULIN e CASTILHO, 2005).

Para a provisão de recursos humanos qualificados, requer-se primeiramente a realização de um planejamento com metodol ogia científica e com parâmetros técnicos definidos s obre o serviço a ser oferecido e os objetivos a serem alcançados. Sem esse planejam ento não s e pode propor categor icamente a real 
necessidade dos recursos humanos e sim imaginar uma situação fictícia direcionando empiricamente as ações dos gestores.

Segundo a Lei $n^{\circ} 7.498$ de 25 de ju nho de 1986 - Le i do Exercício Profissional da Enfermagem (BRASIL, 1986), são funções privativas do enfermeiro a direção, chefia e organização dos se rviços e unidades de enfermagem, sendo de sua inteira responsabilidade o planejam ento, coordenação, execução e avaliação dos serviç os de ass istência de enferm agem. Portanto, a competência para o dimensionamento de pessoal de enfermagem é dos enfermeiros que, identificando e avaliando continuam ente os recursos ex istentes, frente às necessidades da clientela, poderão elaborar propostas adequadas para esse provisionamento.

O Conselho Federal de Enfermagem, em consonância com a Lei do Exercício Profissional, estabelece na Resolução 293/2004 (COFEN, 2004) que o planejamento das necessidades de pessoal ou dimensio namento de pessoal de enfermagem, nas unidades assistenciais, é de competência do enfermeiro, assim como deve ser garantida sua autonomia no gerenciament o desse quadro de pr ofissionais. Embora esteja previsto nas duas instâncias, os enfermeiros têm tido dific uldade para assegurar esta ação.

Gaidzinski (1998) afirma que, na prát ica, a falta de uma metodologia de dimensionamento do pe ssoal de enfermagem que esteja fundamentada em parâmetros definidos em termos operaci onais, fragiliza as argumentações do enfermeiro frente à administração do hospital.

Chenso et al (2004, p.83) complementam que,

(...) o ajuste dos recursos humanos necessários para suprir as demandas do trabalho de enfermagem e das tarefas que são destinadas a estes trabalhadores constitui um estudo que deve levar em conta inúmeras variáveis: quais at ividades de verão ser realizadas, qual a co mplexidade e nece ssidade de q ualificação técnica e specífica, qua I a depend ência de e nfermagem, qual a tecnologia necessária, quais os recursos técnicos e materiais disponíveis e quais as características de ordem técnica, científica e pessoal dos trabalhadores (...) 
O modelo proposto por Gaidzinski (1998) para a realização do dimensionamento do pe ssoal de enfermagem cons idera como variáveis intervenientes desse processo: a complexidade assistencial, identificada por meio da utilização de um instrumento de classifi cação de pacientes; a carga de trabalho da unidade; o tempo efetivo de trabalho e o índice de aus ências previstas ou não ao serviço.

Para o cálculo da carga de trabalho, devemos inicialmente utilizar um sistema de class ificação de pacientes, que esta belece o seu grau de dependência em relação à equipe de enfermagem.

O cálculo da carga de trabalho, de acor do com Gaidzinski, Fugulin e Castilho (2005), é definido pelo produt o da quantidade média diária de pacientes assistidos, segundo o grau de dependência da equipe de enfermagem ou tipo de at endimento necessário, pelo tempo médio de assistência, por paciente, de acordo com o grau de dependência determinado por meio de um sistema de classificação.

Rodrigues Filho (1992) considera que a tomada de decisões referentes à determinação adequada de pess oal de enf ermagem requer necessariamente que o enfermeiro utilize um sistema de classificação de pacientes.

A idéia de classificaç ão de pac ientes já tinha sido $v$ isualizada por Florence Nightingale e a sua u tilização foi inic iada na década de 1960, n os Estados Unidos da América. Contudo, conforme Gaidzinski (1998), foi Ribeir o (1972), a partir dos estudos desenvolvidos no Johns Hopkins Hosp ital, no Brasil, a pioneira na iniciativ a de propor a utiliz ação de u ma classif icação d e pacientes por diferenciaçã o assistencial para o dimens ionamento de pessoal. Esse instrumento foi denominado cálculo par a provimento de pes soal de en fermagem pelos critér ios da ass istência progressiva, com a distribuiç ão da equipe de enfermagem de ac ordo com a complexidade assistencial.

Desde então, pesquisadores brasileiros, tais como Fugulin et al (1994), Fugulin (1997), Perroca (2000), Martin s e Haddad (2000), Bochembuzio e Gaidzinski (2005), entre outros, vêm desenvolvendo estudos de modo a favorecer os enfermeiros na exec ução dess a ativida de, por meio de elabor ação e validação de instrumentos de classificação de pacientes. 
Estudos realiz ados por Gaidzinski

(1998), Nicola ( 2004), entre outros, referem que a qualidade da assistênc ia de enfermagem necessita de um gerenciamento adequado dos recursos humanos, por meio do estabelecim ento das competências necess árias para a realizaç ão dess as atividades. Para t anto, os enfermeiros devem estar instrumenta lizados para o dim ensionamento adequado de suas equipes, sendo a categoriz ação das ne cessidades assistenciais uma c ondição fundamental.

Os instrumentos de classificação são utilizados pela enfermagem para definir a categorização dos pacientes de acor do com a necessidade de cuidados requerida para nortear o processo decisório relaci onado à aloc ação quantit ativa e qualitativ a do pessoal de enfermagem, planejamento de custos e qualidade do cuidado. (PERROCA e GAIDZINSKI, 2003).

Tranquitelli e Padilha (2007) argumentam que os sistemas de classificação de pacientes contribuem tanto para a assist ência quanto para o gerenciam ento das unidades hospitalares quando são de fác il aplicação, validados e precisos e oferecem resultados seguros para a avaliação dos pacientes e da unidade.

A utiliz ação de um sistema de classi ficação de $p$ acientes e stabelece as características da população as sistida, sendo indis pensável para a deter minação das neces sidades de pessoal e alocação de profissionais em qualquer unidade assistencial.

Alward (1983) já referia que além da classificação, a categorização dos pacientes, por meio da utiliz ação de um sistema de c lassificação, permite a visualização do aumento do v olume de trabalho nas unidades, justificando aos administradores dos hospitais, a necessidade de profissionais adicionais .

Segundo Fugulin, Gaidzinski e Kurcgant (2005, p.78)

O conhecimento do perfil assistencial dos pacie ntes pode subsidiar o planejamento e a implementação de programas assisten ciais que melhor atendam às necessidades $d$ esses pacie ntes, auxilia ndo na distribuição diária e na capacita ção dos re cursos humanos de enfermagem para o atendimento de cada grupo de pacientes(...) 
Nicola (2004), em seu estudo sobr e o dimensionamento de pessoal num hospital universitário do Paraná, utilizou o sistema de classificação de pacientes de Perroca (2000), baseado nas necessidades individualizadas de cada pac iente, de acordo com as necessidades humanas básicas afet adas estabelecidas por Horta (1979). O intuito era desvincular o trabalho da equipe de enfermagem da preocupação com a mera realização de ta refas. Considerou relevante a real condição do paciente e a capacidade e experi ência dos profissionais para eficácia do dimensionamento.

Fugulin et al. (1994) propuseram um sistema para class ificação para pacientes de clínica médica, de acor do com o grau de dependência da equipe de enfermagem.

Martins e Haddad (2000) c oncluiram que a validação de um instrumento de classificação de pacientes em um hospital universitário na região norte do Paraná proporcionou aos enfermeiros uma análise profunda no processo de observação das necessidades dos pacientes, tornando-se uma ferramenta de trabalho eficiente na prática diária.

Para conhecer o perfil da clientela atendida num pronto-socorro especializado em afecções cardiov asculares, Farias (2 003) inic ialmente se propôs a utilizar o instrumento de clas sificação c onstruído por Perroca (2000), composto por 13 indicadores críticos de cuidados de enfermagem . Todavia, na prática, esse instrumento demonstrou resultados de subd imensionamento dos cuidados e o autor do trabalho optou por utilizar o sistema de classificação de pacientes proposto por Fugulin (2002), que se revelou mais efet ivo para aquele serviç o. Em seu estudo, constatou uma carga de trabalho exce ssiva, uma defasagem entre o quadro de pessoal de enfermagem existente e o prev isto e, um maior número de clientes assistidos com necessidades de assistência semi -intensiva seguido de clientes de alta dependência.

A fim de identificar o grau de dependênc ia dos usuários atendidos na sala de emergência e na obs ervação do pronto-socorro de um hospital- escola de Curitiba, Montezeli e Lopes (2006) aplic aram uma adaptação do sistema de classific ação de pacientes proposto e validado por Martin s e Haddad (2000), que clas sifica os 
pacientes em quatro graus de dependênci a da enfermagem. Nesse estudo, os autores constataram a predominância de clientes com necessidades assistenciais de alta complexidade (graus III e IV) nas unidades de observação; e de clientes com necessidades de cuidados inter mediários (graus I e II) sendo atendidos na sala de emergência. Isso demonstrou uma descaract erização do serviço e um desvio das funções da equipe de enfermagem nas unidades de emergência do pronto-socorro.

Scapim, Tiveron e Marvulo (2007) , em est udo realizado para o dimensionamento do pessoal de enfermagem em unidade de observação do prontosocorro adulto do Ho spital das Clínicas de Marília, utilizaram um instrumento de classificação de pacientes adaptado de Fugulin (1997) para caracterizar a clientela atendida e obter subsídios para o cálculo do pessoal naquela uni dade. Identificaram clientes totalmente depende ntes, independentes e parci almente dependentes da equipe de enfermagem, com predominânc ia de clientes parcialmente dependentes. Os referidos autores constataram, por me io da utiliz ação dos v alores de horas de assistência de enfermagem es tabelecidos pela Resolução COFEN No 293/2004, um déficit no quantitativ o de pessoal existente, um gr ande número de clientes que não foram computados, mas requeriam assistência de enfermagem . Perceberam a necessidade de uma reflexão sobre o processo de trabalho da equipe e da estrutura física da unidade.

Ressalta-se o trabalho de Fugulin (1997), que estabeleceu uma relação direta entre a c omplexidade assistencial do paciente e as horas de assistência de enfermagem para as categorias profissionais. Essa relação ser ve como parâmetro para o dimensionamento de pessoal estabelec ido pelo Conselho Federal de Enfermagem, atualmente por meio da Re solução COFEN N 293/2004 (COFEN, 2004), que determina os parâmetros mínimos para o dimensionamento do quadro de pessoal de enfermagem nas instituiç ões de saúde. Vale lembrar que essa Resolução é fundamentada na complexidade a ssistencial da clientela e esse é um dado ainda pouco estudado nas unidades de pronto-socorro.

Outra vari ável interv eniente no proc esso de dimensionament 0 , consoante Gaidzinski (1998), é o tempo diário efet ivo de trabalho da equ ipe de enfermagem. De acordo com o autor, os trabalhadores nã o são igualmente produtivos em todo o turno de trabalho, pois necessitam atender s uas necessidades fisiológicas, possuem 
períodos de descanso, trocam informaç

ões não ligadas ao trabalho, realiz

am deslocamentos des necessários, entre outras atividades não diretamente relacionadas às suas atividades profissionais.

Partindo d esse press uposto, Fu gulin ( 2002) utilizo u um índice de $85 \%$ d e produtividade das horas de trabalho, avaliado como um índice exc elente por Biseng (1996), para dimensionar e avaliar o quadro de enfermeiras da Unidade T erapia Intensiva pediátrica do Hospital Universitário da Universidade de São Paulo.

Para Mello (2002), o tempo utiliza do $p$ ara desempenhar atividades $n$ ão específicas da enfermagem, a motivação, o desempenho do trabalhador, o uso de tecnologia e os métodos de trabalho que sustentam o seu des envolvimento, são fatores importantes que influenciam diretamente a produtividade dos profissionais.

Bordin (2008) realizou estudo para i dentificar e analisar a distribuição do tempo de t rabalho de enferme iras em unidades de inter nação médico-cirúrgica do Hospital e Maternidade São Camilo Pompeia, um hospital privado localizado na zona oeste do município de São Pa ulo e cons tatou que, nesse serviço, as enfermeiras utilizam $17,8 \%$ do tempo de trabalh o para a realiz ação de atividades classificadas como de tempo pessoal (alimentação, descanso, eliminações fisiológicas, chamadas telefônicas pessoais e socialização com colegas) valor aproxim ado ao utilizado por Fugulin (2002).

Para suprir a necessidade de c obertura das ausências utiliza-s e o Índice de Segurança Técnica (IST), que é outr a variável a ser considerada no dimensionamento de pessoal. Este valor percentual é destinado à cobertura das taxas de absenteísmo (ausências não programadas ao trabalho - faltas, licenç as saúde, vagas por demissão, suspensões) e das ausências por benefícios (ausências programada ao trabalho - (folgas, férias, fe riados, licenç a prêmio). A Resolução COFEN No 293/2004 estabelec e um percentual mínimo de 15\% para o índice de segurança técnica, recomendando que este deve ser adequado à realidade de cada instituição

Gaidzinski et al (1998) já refe renciavam que o elevado percentual das ausências previstas é o que mais inte rfere no quadro de pessoal de enfermagem que está trabalhando, principalmente pelo fato de representar um direito adquirido, 
independente do regime formal de cont ratação e por normalmente não haver profissionais para a cobertura desse tipo de ausência, causando sobrecarga de trabalho e insatisfação.

Os mesmos questionamentos foram feit os por Farias (2003, p.40) em sua tese de doutorado. Embora realizada em um pronto-socorro especializ ado em afecções cardiovasculares, estes também inquietaram os enfermeiros da unidade de pronto-socorro de um hospital geral.

De acordo com esse autor, os dados relativos às horas des pendidas na assistência de enfermagem não foram efet ivamente calculados devido à diversidade de atividades e atendimento.

\begin{abstract}
Diante disso, question amentos foram surgindo, para os quais não tínhamos respostas, a saber: quanto te mpo dispomos aos pacientes/clientes que requerem assistên cia de enfermagem de baixa, média ou alta complexidade? E par a os que ficam e $\mathrm{m}$ observação por algumas horas? E os que realmente permanecem internados na unidade? Qual o te mpo necessário para a enfermeira orientar o cliente/família em um Pronto Socorro?
\end{abstract}

\title{
1.1 O Pronto-socorro
}

O pronto-socorro é uma unidade do ho spital destinada à assistência a pacientes externos com ou sem risco de morte, cujos agravos à saúde necessitam de atendimento imediato; $f$ unciona nas 24 horas do dia e dispõe de leitos de observação. (BRASIL, 1987).

Para tanto, as unidades de pronto-socorro, públicas e privadas, devem estar estruturadas para prestar assistência adequada em sit uações de urgência, caracterizada por casos que nec essitam de atendimento rápido, porém sem risco de morte iminente e, emergência, com risco imediato de morte.

Além de assegurar as manobras de sustentação de vida, essas unidades têm representado a porta de entrada para os us uários que buscam resolubilidade para demandas que deveriam ser atendidas em outros níveis de atenção à saúde. 
Muitos casos deveriam receber atendimento em unidades de prontoatendimento que, segundo o Mi nistério da Saúde (BR ASIL, 1987), é a unidade destinada a prestar, dentro do horário de funcionam ento do estabelec imento de saúde, ass istência a doentes, com ou sem risco de vida, cujos agravos à saúde necessitam de atendimento imediato.

O Ministério da Saúde, em sua Portaria $n^{\circ} 2.048$, de 05/11/2002, publicada no Diário Oficial da União $n^{\circ} 219$, de 12/11/2002 (BRASIL, 2002), define que:

\begin{abstract}
A assistên cia às urgên cias se dá, ainda hoje , predominantemente nos serviço s que fun cionam exclusivamente para este fim os tradicionais pronto-socorros - estando estes adeq uadamente estruturados e equipados ou não. Abertos nas 24 horas do dia, estes serviços acabam por funcionar co mo porta-de-entrada do sistema de saúde, acolhendo pacientes de urgência propriamente dita, pacientes com quadros percebidos como urgências, pa cientes desgarrados da atenção primária e especializada e as urg ências sociais. Ta is demandas misturam-se nas unidad es de urgên cia superlotando-as e comprometendo a qualidade da assistência pr estada à população. Esta realid ade assist encial é, ainda, agra vada por problemas organizacionais deste s serviços como, por exemplo, a falta d e triagem de risco, o que determi na o atendimento por ordem de chegada sem qualquer avaliação prévia do caso, acarretando, muitas vezes, graves prejuízos aos pacientes(...)
\end{abstract}

De acordo com Menzani (2006), a unidade de pronto-socorro possui uma demanda espontânea, muitas vezes maior que a prevista, resultando em condições de trabalho nem sempre adequadas, decorr entes de uma dinâmica int ensa de atendimento.

Para atender demandas circunstanciais e muitas vezes inesperadas, a unidade de pronto-socorro necessita obrigatoriament e de uma equipe de enfermagem estruturada e capacita da, tanto quantit ativamente quanto qualitativamente.

Segundo Dal Pai e Lautert (2005), a qualidade da ass istência não é garantida somente com o uso de tecnologias, pois é influenciada decisivamente por aspectos relacionados ao objeto e à força de trabalho envolvidos no processo. 
Para Awada e Rezende (2007), o pronto- socorro representa o último reduto para atendimento de pacient es desamparados pelo s istema de saúde e que são atraídos para esse serviço em busca de consultas de rotinas devido à ineficiência na atenção primária ou secundária.

Nesse sentido, a constatação de Garcia (2009, p.18), par a as unidades de emergência, pode ser validada para as unid ades de pronto-socorro de uma maneira geral, quando o autor refere que,

\begin{abstract}
(...) a problemática $r$ elacionada ao planejamento, alocação e avaliação $d$ e recursos humanos de enfermagem assume maiores proporções devido, entre outros aspectos, à dinâmica de trabalho da unidade; à diversidade das ações desenvolvidas; à rotatividade de pacientes e à esca ssez de parâmetros, que dificultam a operacionalização dos métodos convencionais de dimensionamento de pessoal de enfermagem.
\end{abstract}

Considerando também que a definição rigorosa do que vem a ser urgência e emergência não é c lara para a grande par te da populaç ão, o atendim ento nos pronto-socorros acaba abrangendo toda um a demanda reprimida que não encontra acolhimento em outros serviços (ambul atórios, pronto at endimento, unidades básicas de saúde, etc). Trat a-se de pacientes com queixa s crônicas e sociais, que procuram esse serviço e sobrecarregam as equipes multiprofis sionais, inclusive a equipe de enfermagem.

Montezeli e Lopes ( 2006), em estudo para implantação de um sistema de classificação de pacientes no pronto-socorro de um hospital-escola de Curitiba, constataram que havia um fluxo inadequ ado de pacientes na unidade, advinda de uma demanda exc essiva e inc ompatível com os leitos de internação dis poníveis, principalmente de terapia intensiva. $E$ sse fluxo descaracteriza o serviço de emergência, uma vez que o pessoal de enf ermagem devia prestar assistência específica de unidades de internação ou de terapia int ensiva. O que se vê é a presença de pacientes internados que de veriam ser encaminhados para outras unidades. 
Para Jung et al. (2003), a pr ocura pelos serviços de emer gência vem crescendo acentuadamente desde a déca da de 50 do século passado, tendendo a continuar aumentando. De acordo com os autores, a realidade vivenciada demonstra que a população requer serviços de saúde estruturados e pr ovidos de recursos humanos, materiais e tecnológicos nec essários para que sejam resolutivos e ofereçam respostas às diversas demandas.

Dessa for ma, a imprevisibilidade da demanda aliada à gr avidade e à complexidade torna esse cenário um ver dadeiro des afio e um dos setores mais importantes de um hospital, onde a ass istência pr estada deve primar por uma qualidade de nível elevado e ser qualificada para todas as adversidades possíveis, a fim de responder às expectativas dos usuários.

Em decorrência des sa situação, viv enciamos prontos-socorros lotados e, diferentemente das unidades de internação que poss uem número fixo de leitos, o pronto-socorro não restringe o acesso do us uário, ocasionando a ativação de leitos extras que são operacionalizados pelos corredores na forma de macas.

Menzani (2006) refere que, no Brasil, o fluxo invertido de pacientes entre os serviços de saúde da rede básica e os se rviços da alta complexidade resultam frequentemente em situações de superlotação dos pronto-socorros que pass aram a ser o princ ipal local de triagem dos serviços de saúde, sobrecarregando a equipe multidisciplinar desses serviços.

Tomando como pano de fundo toda esta problemát ica que vem ocorrendo nos prontos socorros em relação ao aum ento da demanda e a difícil organização da hierarquização dos serviços de saúde, a diversidade de necessidade de cuidado de enfermagem, e da v ivência direta do proc esso de trabalho em unidades de pronto socorro, e a instituição em estudo não ter ainda um diagnóstico da situação, desencadeamos o estudo que tem por objetivo:

\footnotetext{
Caracterizar o perfil assistencial dos pacientes adultos atendidos na unidade de pronto-socorro de um hospital geral como um dos subsídios para o dimensionamento do pessoal de enfermagem.
} 
Metodologia 


\title{
2. METODOLOGIA
}

\subsection{DELINEAMENTO METODOLÓGICO}

Este estudo foi desenvolvido na forma de uma pesquisa exploratória que, segundo Gil (2002, p.41), (... ) "tem como objetivo pr oporcionar maior familiaridade com o problema, com vistas a torná-lo mais explícito ou a constituir hipóteses".

Utilizou-se o método do estudo de caso que permite o escla recimento do objeto em seus múltiplos aspectos.

Polit e Hungler (1995, p.125) definem que

\begin{abstract}
Estudos de casos são investigações em profundidade de uma pessoa, gru po, institu ição ou outra unidade so cial. O pesquisador que realiza um estudo de caso $t$ enta analisar e compreender as variáveis importantes ao histórico, desenvolvimento ou cuidad o dispensado ao indivíduo ou a seus proble mas (...)Sem dúvida alguma, a maior vantagem dos estudos de caso é a prof undidade possível, quando está sendo investigada uma quantidade limitada de pessoas, instituições ou grupos.
\end{abstract}

\subsection{LOCAL DO ESTUDO}

A pesquis a foi realizada em um hospital geral, após a autorização institucional. (Apêndice 1)

A unidade local do estudo, um pronto-soco rro geral, adulto, clínico e cirúrgico, desse hospital geral, público estadual, localizado no Distrito do Itaim Paulista, região do extremo leste do municípi o de São Paulo ( $F$ igura 1$)$ e que faz div isa com os municípios de Itaquaquecetuba, Poá e Ferraz de Vasconcelos.

O município de São Paulo pos sui $1.509 \mathrm{~km}^{2}$ de área e uma população de 10.998.813 habitantes, e uma divisão administrativa dos serviços de saúde em cinco Coordenadorias Regionais de Saúde - CRS (N orte, Sul, Sudes te, Centro-Oeste e Leste). A Coordenadoria Regional Leste tem dentro de seus li mites uma população de 2.543.813 habitant es. O Distrito do Itaim Paulista possui segundo ess a divisão administrativa, uma população de 240.295 habitantes. A Região Leste não foge das características de região pobre do Municípi o de São Paulo, onde há um acúmulo de 
problemas na área da Saúde, Educação, Moradia, Trabal ho, Segurança, etc (SÃO PAULO, 2009).

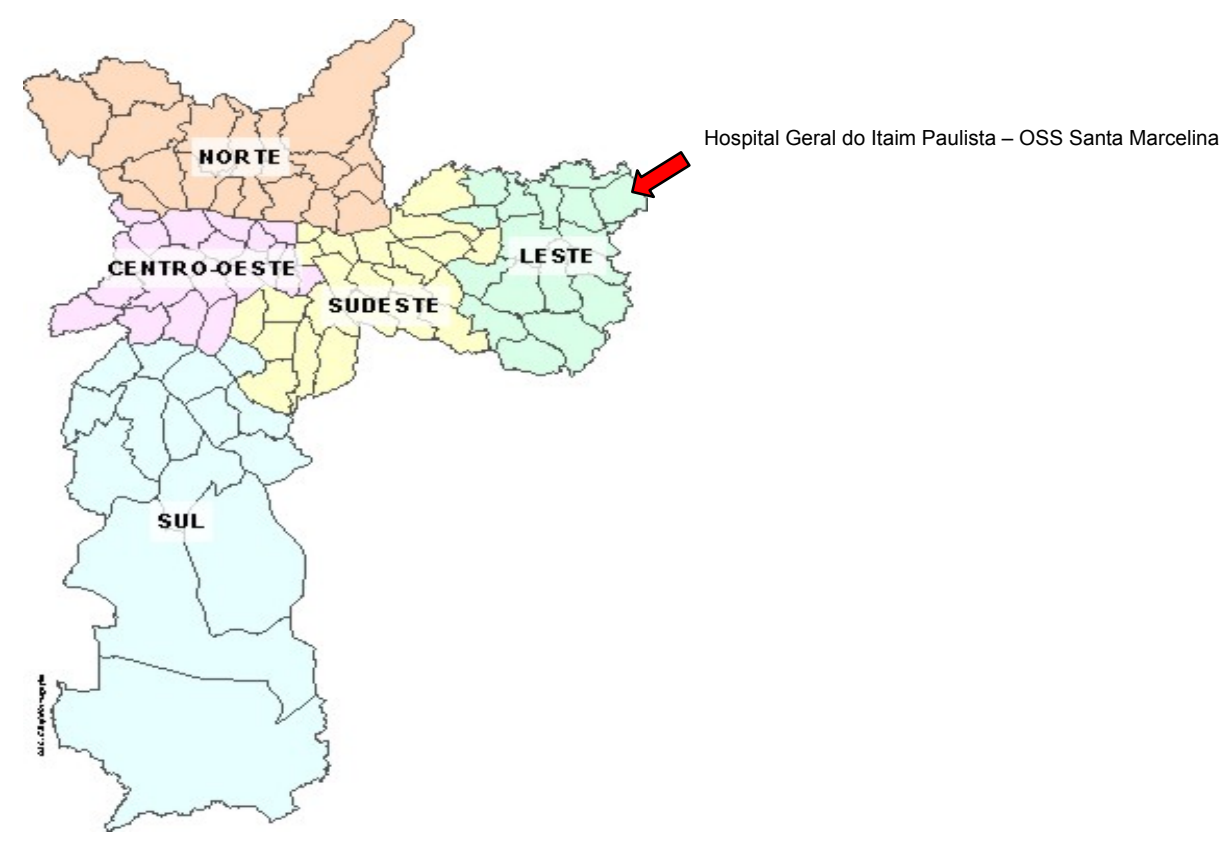

Fonte: http://portal.prefeitura.sp.gov.br/secretarias/saúde/organizações/0009

Figura 1 - Distribuição das Coordenadorias de Saúde do Município de São Paulo por regiões geográficas, São Paulo, 2009

\subsubsection{A Organização Social de Saúde Santa Marcelina}

A Organização Soc ial de Saúde é uma entidade jurídica de direito privado, sem fins lucrativos e com comprovada experiência em serviços de saúde que administra por meio de um contrato de gestão com um hospital públic o (Yamada et al, 2002). No present e caso, o hospital é da esfera do Governo do Estado de São Paulo e garante $100 \%$ de atendimentos à população pelo Sistema Único de Saúde.

O contrato de gestão é um instrument o jurídico-legal de parceria entre o poder público e o s etor privado para a implementação e operacionalização de serviços de saúde oferecidos à população.

Nesse modelo de gestão, o Poder Públic o faz o repasse dos recursos e bens necessários, e os parceiros garantem a execução das atividades, seguindo uma lógica de autonomia, flexibilidade e agi lidade. O poder público deverá fazer o 
controle do trabalho, com base no cumprimento de metas, de prazos e da análise de indicadores de produção de s erviços de s aúde, de c obertura da população e de qualidade dos serviços contratados, sempre com o objetivo de gerar impacto positivo na oferta de serviços à população (CARNEIRO JÚNIOR, 2002).

Em 1997, a Secretaria de Estado da Saúde de São Paulo est abeleceu a forma de parceria entre Organizações So ciais de Saúde e o Poder Público para minimização das dificuldades que enfrentava. A perspectiva era otimizar os recursos disponíveis para o atendim ento do Sistema Único de $S$ aúde, visualizando a criação de mecanismos inovadores de gestão de serviç os hospitalares, a fim de propiciar mecanismos de agiliz ação administrativa nas áreas de gestão de pessoas; gestão de recurs os materiais e serviços e ac ompanhamento da pr odutividade e da qualidade do atendimento e satisfação do us uário. Entre os anos de 1997 e 1998, foram concluídos alguns hospitais est aduais e a Secretaria optou por entregá-los à população sob a gerência de Organizaç ões Sociais, que se caracterizam por serem entidades sem fins lucrativos, de reconh ecido saber, capacidade e experiência gerencial, conforme os termos da Lei Complementar № 846 de 04/ 06/1998 (YAMADA et al, 2002).

\subsubsection{O Hospital Geral do Itaim Paulista}

O Hospital Geral do Itaim Pau lista iniciou suas atividades em agosto de 1998. Seu gerenciamento era realiz ado, desde então, pela Organi zação Social de Saúde Santa Marcelina que faz par te de um complexo de saúde, administrado por uma entidade religiosa católica, constituído por mais três hospitais ( dois no m odelo de OSS, sendo um do gover no do Estado de São Paulo localizado no município de Itaquaquecetuba e outro do Municí pio de São Paulo, além de um hospital de porte extra, próprio, de alta complexidade, c om 700 leit os de internação), Unidades Básicas de Saúde da Família e Unidades de Atendiment o Médico Ambulatorial (AMA) que, no município de São Paulo, são responsáveis pela execução de serviços de atendimento médico não agendado para portadores de patologias de baixa e média complexidade, além de encaminhamentos de exames, medicação, curativos e suturas, podendo ainda oferecer outros se rviços de ac ordo com plano de trabalho especifico. (SANTA MARCELINA, 2009) 
O Hospital Geral do Itaim Paulista possu i 260 leitos de internação, sendo dez na unidade de terapia intens iva adulto, di stribuídos nas espec ialidades de clínica médica, cirurgia ger al, ortopedia, pediatria , ginecologia, obst etrícia, psiquiatria e neonatologia, além de um ambulatório de especialidades médicas (ortopedia, psiquiatria, ginecologia, cirurgia geral e vascular). (SANTA MARCELINA, 2009)

É caracterizado pela atenção sec undária de média complexidade e maternidade e os atendimentos são realiz ados de acordo com o contrato de gestão, 100\% pelo Sistema Único de Saúde. (YAMADA et al, 2002)

O Hospital Geral do Itaim Pau lista foi submetido a um sistema de avaliação e certificação da qualidade de serviços de saúde, voluntário, periódico e reservado e, a partir de julho de 2008, recebeu o título de Hospital Acreditado Pleno, conferido pela Organização Nacional de Acreditação (ONA), que c onfere certificações de qualidade aos serviços hospitalares. (ORGANIZAÇÃO NACIONAL DE ACREDITAÇÃO, 2009)

\subsubsection{A Unidade de Pronto-socorro do Hospital Geral do Itaim Paulista}

Localizada no andar t érreo do hospital, a unidade de pronto-socorro trabalha com demanda espontânea do usuário, sendo priorizados os atendimentos de acordo com a gravidade e aqueles encaminhados pelas unidades, às quais o pronto-socorro serve como referência.

$\mathrm{Na}$ área do pronto-socorro, estão lo calizados dois consultórios par a atendimentos de casos clínicos, dois para casos cirúrgicos, dois para a pediatria, um para a psiquiatria, um para a ortopedia e no quart o andar há um consultório para atendimentos de ginecologia e obstetrícia.

Além dos consultórios, o pronto-socorro tem em sua planta física sala de recepção e espera, sala de qualificação de riscos, sala de gesso, duas salas de sutura para pequenos procedim entos ambula toriais, uma sala de medicação para crianças, uma para adultos, sala para i nalação, local destinado à observação dos usuários que estão recebendo infusões endovenosas, uma farmáci a e um almoxarifado satélites e um setor de radiologia e tomografia computadorizada. 
A unidade possui planta física adequada para o atendimento de dez pacientes na sala de emergência e 24 pacientes dis tribuídos por três sal as de obs ervação, sendo uma sala com oito leitos fixos para pa cientes do sexo feminino; uma sala com oito leitos fixos para pacientes do sexo masculino e uma sala que pode ser utilizada de acordo com a demanda de internação, observação ou reavaliação médica.

Usuários s em urgências são encaminhados aos consultórios médicos das clínicas correspondentes para consulta. Após a consulta médica podem:

- Receber alta médica do consultório;

- Receber alta médica após medicação;

- Ser encaminhados para medicação, $r$ ealização de exames e retorno ao consultório para reavaliação médica e alta ou observação, ou ainda;

- Ser encaminhados diretamente para internação hospitalar.

Nos casos de observ ação e int ernação hospitalar, a equipe de enfermagem realiza a admissão desses pacientes na uni dade e dá continuidade à assistência de enfermagem necessária.

Os casos de emergência são encam inhados diretamente às salas de atendimento de emergências (casos clínic os, cirúrgicos, pediátricos, etc). Habitualmente, os usuários trazidos ao pronto-socorro pelos serviços de resgate dos bombeiros da polícia militar ou de atendim ento móvel de urgênc ia (SAMU) devem ser atendidos com prioridade.

A figura 2 demonstra o fluxo do atendim ento dos pacientes adultos no prontosocorro, desde a recepção até a alta médica ou internação hospitalar ou observação. 


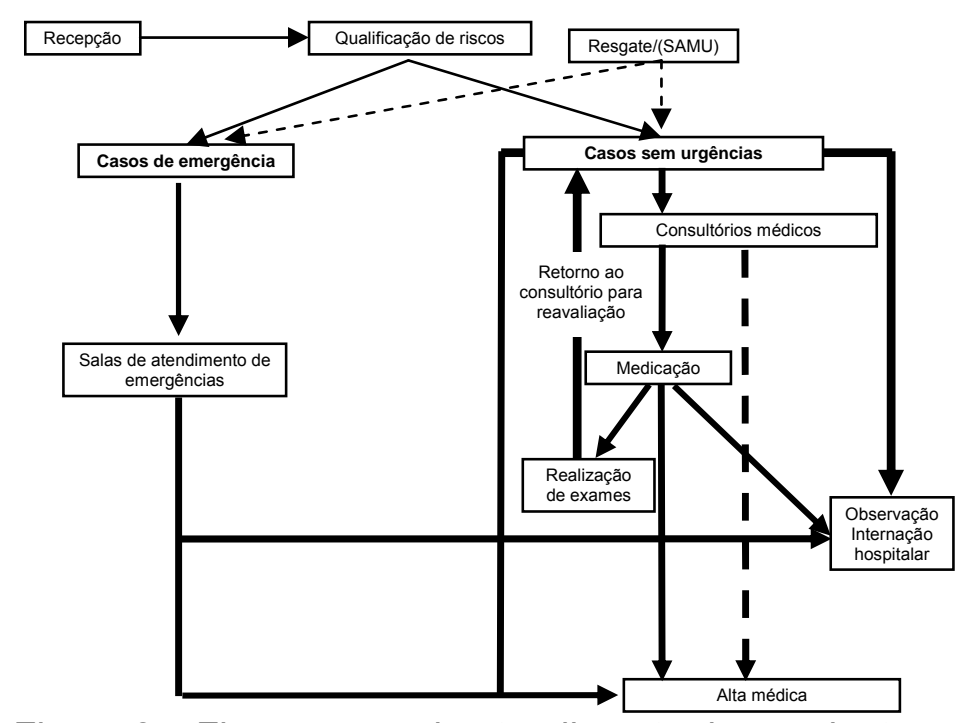

Figura 2 - Fluxograma de atendimento dos pacientes adultos do pronto-socorro d o Hospital Geral do Itaim Paulista, OSS Santa Marcelina. São Paulo, 2009

A caracterização da unidade caso, em relação ao número de leitos e de atendimentos realizados no ano de 2008 , foi feita por meio de dados colet ados no setor de estatística da inst ituição de saúde onde foi realizada a pesquisa, denominado Serviço de Prontuário do Paci ente - SPP (Apêndic e 2) e apresentada na tabela 1.

Tabela 1 - Caracterização da Unid ade de Pronto-socorro em relação ao número de leitos e do número de atendimentos realizados no ano de 2008. São Paulo, 2009

Leitos de observação adulto no Pronto-socorro

Leitos na sala de emergência adulto

Média mensal de atendimentos - Geral

Média mensal de atendimentos - Pronto-socorro adulto

Média mensal de internações - Geral

Média mensal de internações - Pronto-socorro adulto

Fonte: Serviço de Prontuário de P aciente - SPP, Hospital Geral do Itaim Paulista, OSS Santa Marcelina, São Paulo, 2009 
Pode-se observar na tabela 1 que a Unidade de Pronto-so corro possui 24 leitos de Observação para pacientes adultos e dez leitos na un idade de atendimento de emergências, destinados às manobras de sustentação da vida dos pacientes com risco iminente de morte e que necessitam de cuidados intensivos e semi-intensivos, em função da inst abilidade hemodinâmi ca e da necessidade de cuidados permanentes de enfermagem, além da ne cessidade de permanecerem internados no PS, por não hav er leitos na UTI em número suficiente para a demanda do hospital.

Constata-se que em 2008, houve uma média mensal de 17.498 atendimentos gerais (adulto ${ }^{1} \mathrm{e}$ infantil ${ }^{2}$ ) isto é, pacientes que pass aram em consulta médica nos consultórios ou nas salas de emergência. Dessa média mensal total, 13.798 eram pacientes adultos. Ainda ocorreu uma médi a mensal geral de 1.320 internações de pacientes que necessitaram permanec er em observaçã o ou que foram encaminhados às enfermarias ou ao centro cirúrgico, sendo que desses, 1.081 eram adultos que ficaram internados pelas espec ialidades de Clínic a Médica, Cirúrgica, Ortopédica e Psiquiátrica.

Ainda de acordo com o serviço de pront uário de paciente, a mesma unidade de pronto-socorro apresenta uma média de 17.800 atendi mentos gerais mensais, com uma média de internações de 635 pa cientes por mês no ano de 2007. (SANTA MARCELINA, 2008)

Embora oficialmente a unidade possu a dez leitos para atendimento e internação na sala de emergência e 24 leit os de inter nação para observação, esse serviço trabalha com demanda espontânea do usuário sem um serviço de regulação, havendo a ocorrência de exce dente de internações em re lação ao número de leitos oficiais.

Em relação aos profissionais de enf ermagem lotados no pronto-socorro para o período de 24 horas, podemos observa r, na tabela 2, por meio dos dados fornecidos pelo Departamento de Enfermagem da instituição (Apêndice 3), o número total e a distribuição percentual por níveis de formação.

\footnotetext{
${ }^{1}$ Pacientes a partir de 12 anos de idade

2 Pacientes até 11 anos 11 meses e 29 dias
} 
Tabela 2 - Caracterização da Unidade de Pr onto-socorro em relaçã o ao número total d e profissionais de enfermagem para as 24 horas do dia, distribuídos em quatro plantões. São Paulo, 2009

\begin{tabular}{lrr}
\hline Profissionais de enfermagem & $\mathrm{N}^{\circ}$ & $\%$ \\
\hline Enfermeiros & 14 & 9,46 \\
Técnicos de enfermagem & 11 & 7,43 \\
Auxiliares de enfermagem & 123 & 83,11 \\
\hline Total 148 & & 100,00 \\
\hline
\end{tabular}

Fonte: Departamento de Enferma gem. Hospital Geral do Itaim Paulista, OSS San ta Marcelina, São Paulo, 2009

A tabela 2 apresent a a c aracterização do pronto-socorro em função do número total de profissi onais de enfermagem par a o período de 24 horas, distribuídos em quatro plantões e por cat egoria, inclusive os de férias, folgas e licenças.

Atualmente, dos 14 enfermeiros aí lotados, dois estão no setor de qualificação de riscos e prioridades para atendimentos, que funciona das 7 às 19 horas. Nesse setor é realizado o ac olhimento com a esc uta da queixa e o motivo da procura do serviço; são verificados os sinais vita is e de acordo com a av aliação do risco e gravidade de cada c aso, o usuário é di recionado para o atendimento. Os 12 enfermeiros restantes estão distribuídos igualmente entre os quatro plantões (três no matutino, três no vespertino, três no noturno "par" e três no "ímpar").

Os enfermeiros de cada plantão realizam escala de revezamento entre as unidades de emergência e observação adul to e infantil e assumem a assistência direta aos pacientes ; a Sistematizaç ão da Assist ência de Enfermagem que é realizada por meio de um sistema el etrônico informatizado; as questões administrativas e a responsabilidade técnica pela equipe de enfermagem.

Dos 11 técnicos de enfermagem, dois são escalados no plantão matutino, três no vespertino, três no noturno "par" e três no "impar", sempre nas unidades de atendimento de emergência adulto e infantil.

A unidade possui um total de 123 aux iliares de enfermagem, sendo dois exclusivamente para a realização de elet rocardiogramas no período diurno, quatro para remoção de clientes internados que necessitam de procedimentos externos não realizados na instituiç ão, distribuídos nos plantões diurno e noturno em jornadas 
especiais de trabalho $12 \times 36$ (12 horas de trabalho por 36 horas de descanso), 32 no período matutino, 31 no vespertino, 27 no noturno "par" e 27 no "ímpar".

Enfermeiros, técnicos e auxiliar es de enf ermagem dos plantões diurnos realizam jornadas de seis horas diárias e jornada sem anal de trabalho de 36 horas, enquanto os dos plantões noturnos cumprem jornadas especiais de trabalho $12 \times 36$.

Os plantões diurnos (matutino e ve spertino) contam com um número de auxiliares de enfermagem maior que os pl antões noturnos, em função de grande parte dos procedimentos de rotina ser $r$ ealizada durante o di a, restando ao período noturno os procedimentos de urgência e emergência e a assistência de enfermagem aos pacientes aí internados ou em observação.

Vale ressaltar que nem todos os pr ofissionais da equipe de enfermagem do pronto-socorro estão aloc ados em ativ idades onde ocorrem internações de pacientes adultos (unidades de emergência e observação), uma vez que a unidade dispõe de um pronto-socorro infantil.

\subsection{SUJEITOS DA PESQUISA}

Os sujeitos da pesquisa foram os pac ientes adultos atendidos na unidade de emergência e os que ficaram em observação ou internados nas salas de observação do pronto-socorro durante o período da coleta dos dados.

Embora parte dessa unidade seja destinada a atendimentos pediátricos, estes não partic iparam como sujeitos, uma vez que o instrum ento utiliz ado para a caracterização da clientela, de acordo co m Fugulin, Gaidzinsk i e Kurcgant (2005), não atende integralmente às características do paciente pediátric o, sendo necessária a caracterização dessa clie ntela posterior mente por meio da utilização de instrumento apropriado.

\subsection{INSTRUMENTO DE COLETA DE DADOS}

Partindo da experiência de Far ias ( 2003), que realizou estudo do perfil assistencial da clientela de um pronto-socorro especializado em afecções cardiovasculares para o dimensionamento de pessoal de enfermagem, e que inicialmente utilizou o inst rumento de Perroca (2000) e verificou uma class ificação 
subdimensionada dos pacientes, optamos pel a utilização do ins trumento proposto por Fugulin (2002) (ANEXO 1) para i dentificar, do ponto de vista da equipe de enfermagem, as características do perfil as sistencial, dos clientes adultos atendidos no pronto-socorro do Hospital Geral do Itaim Paulista.

Esse instrumento de classificação de pacientes é o resultado da atribuição de pesos aos níveis de dependênc ia do instrumento de classi ficação de Fugulin et al (1994), que foi desenvolvido e implantado na uni dade de clínica médica do Hospital Universitário da Univ ersidade de São Paul o (HU-USP). Ele av alia nove áreas de cuidado (Estado mental, Ox igenação, Sinais Vitais, Motilidade, Deambulação, Alimentação, Cuidado Corporal, Eliminação e Terapêutica).

Fugulin (2002) estabelece, para c ada uma das áreas de cuidado, pontuações que variam de um a quatro, de acordo com a gradação da complexidade assistencial apresentada pelo pac iente no momento da avaliação, sendo a pontuação um a de menor complexidade e quatro a de maio $r$ complexidade ass istencial requerida, indicando menor ou maior dependência em relação à equipe de enfermagem.

Ao final da avaliação, realiza-se a so ma dos pontos atribuídos e verifica-se o grau de dependência em relação à equ ipe de enf ermagem ou de complexidade assistencial em função das cinco categoria s estabelecidas pelo instrumento, sendo nove a menor e 36 a maior pontuação possível:

- Cuidados intensivos: (entre 32 e 36 pontos) pacientes recuperáveis, com risco iminente de morte, sujeitos à instabili dade de funç ões vita is, que requeiram assistência de enfermagem e médica permanente e especializada;

- Cuidados semi-intensivos: (entre 27 e 31 pontos) pacientes recuperáveis, sem risco iminente de morte, sujeitos à instabilidade de funções vitais que requeiram assistência de enfermagem e médica permanente e especializada;

- Alta dependência: (entre 21 e 26 pontos) pacientes crônicos que requeiram avaliações médicas e de enfer magem, es táveis sob o ponto de vista clínico, porém com total dependência das ações de enfermagem quanto ao atendimento das necessidades humanas básicas; 
- Cuidados intermediários: (entre 15 e 20 pontos) pacientes estáveis sob o ponto de vista c línico e de enfermagem que requeiram avaliações médicas e de enfermagem, com parcial dependência de enfermagem para o atendimento das necessidades humanas básicas e;

- Cuidados mínimos: (entre 9 e 14 pontos) pacientes estáveis sob o ponto de vista clínico e de enfermagem que requeiram avaliações médicas e de enfermagem, mas fisicamente autossuficient es quanto ao atendiment o das necess idades humanas básicas.

\subsection{TÉCNICA DE COLETA DE DADOS}

A coleta de dados foi realizada por um período de 30 dias, no mês de janeiro de 2009 , sempre no período da manhã, entre $7 \mathrm{~h} 30 \mathrm{~min}$ e $12 \mathrm{~h}$.

Embora a Resolução COFEN 293/2004 es tabeleça um período entre quatro a seis meses para a coleta de dados para clas sificação e caracterização dos pacientes nas unidades, es tudos estabelecem períodos menores para a coleta de dados, de sde que u tilizem per íodos com of erta constante e que repre sente a produção que se deseja avaliar.

Tanaka e Melo (2004) estabelecem como o período mais prático, a utilização da "semana típica" que não deve ser precedida ou seguida de feriados ou estar situada em meses atípicos de férias.

Para Gaidzinski, Fugulin e Castilho ( 2005), podemos classificar os pacientes uma vez ao dia, por um período mínim o de 30 (trinta) dias desde que o mês da coleta seja típico, ou seja, não esteja exposto a qualquer tipo de ocorrência qu e interfira na oferta de serviços e na quantidade de pacientes assistidos.

Após aprovação do Comitê de Ética em Pesquisa da Escola de Enfermagem de Ribeirão Preto da Universi dade de São Paulo não foi iniciada a coleta dos dados por ser um período atípico com feriados que normalmente interferem na demanda do pronto-socorro. 
Embora os autores supra citados estabeleçam a semana ou mês típico como período de coleta ou para a classificaç ão de pacient es, o mês de janeiro de 2009 não apresentou, no pronto-socorro, nenhum a variação significativa que o descaracterizasse como atípico para aquele setor.

Dessa maneira, o instrumento foi aplic ado, após explicação dos objetivos da pesquisa e anuência, com leitura e assinat ura do Termo de Cons entimento Livre e Esclarecido pelo suj eito ou res ponsável l egal (Apêndice 4), a todos os pacientes adultos at endidos nas unidades de em ergência e de obser vação, masculina e feminina do pronto-socorro.

Os dados foram coletados pelo pesquis ador e por alunos $v$ oluntários do oitavo semestre do curso de graduaç ão em enf ermagem da Faculdade Santa Marcelina - FASM, que, após realizaç ão de treinamento e capacitação, avaliavam o paciente e o enquadravam na me lhor categoria por área de cuidado, de acordo com o instrumento de classificação.

Todos os instrumentos preenchidos foram entregues ao pesquisador para conferência e registro em instrumento próprio. (Apêndice 5)

\subsection{ANÁLISE DOS DADOS}

Os dados coletados por meio do instrumento de classificação de pacientes de Fugulin (2002) foram digit ados pelo próprio pesquis ador, em uma planilha Exc el e armazenados em um banco de dados.

Para a sua interpretação utiliz ou-se a estatística básica e par a a discus são dos resultados, bibliografia apropriada.

\subsection{ASPECTOS ÉTICOS}

O projeto de pesquis a foi submetido à apreciação do Comitê de Ética em Pesquisa da Escola de Enfermagem de Ribeirão Preto da Un iversidade de São Paulo e foi aprovado em 15 de dezem bro de 2008 (Of. CEP-EERP/USP - 
274/2008). Recebeu autorização da instit uição de s aúde onde foi desenvolvido o estudo para a sua realização (Apêndice 1) e, obedeceu à Resolução nº 196/1996 do Conselho Nacional de Saúde que regul amenta a pesquisa envolvendo seres humanos. (BRASIL, 1996) 
-Apresentação e discussão dos dados 


\section{APRESENTAÇÃO E DISCUSSÃO DOS DADOS}

A seguir s erão apresentados os dados co letados por meio da aplic ação do instrumento de clas sificação de pacient es de Fugulin (2002), realizada por um período de 30 dias, a todos os pacientes com 12 anos ou mais de idade, dos sexos masculino e feminino, atendidos ou in ternados nas salas de emer gência e observações do pronto-socorro.

\subsection{CARACTERIZAÇÃO DO PERFIL ASSISTENCIAL}

A tabela 3 apresenta o número total de avaliaç ões e a frequênc ia de distribuição quanto à complexidade assistencial dos pacientes adultos no período de 30 dias no Pronto-socorro, de acordo c om o instrumento de classific ação por complexidade assistencial e gr au de dependênc ia da equip e de enfermagem proposta por Fugulin (2002) que estabe lece cinc o categorias de com plexidade assistencial.

Tabela 3. Número total de avaliações dos $p$ acientes ad ultos e freq uência de $d$ istribuição quanto ao grau de dependência assistencia I no período de 30 dias no Pronto-soco rro. São Paulo, 2009

\begin{tabular}{lrr}
\hline Complexidade Assistencial & $\mathrm{N}^{\circ}$ & $\%$ \\
\hline Intensivo & 91 & 7,41 \\
Semi-intensivo & 75 & 6,11 \\
Alta dependência & 245 & 19,95 \\
Intermediário & 272 & 22,15 \\
Mínimo & 545 & 44,38 \\
\hline Total 1.228 & & 100,00 \\
\hline
\end{tabular}

Foram realizadas 1.228 avaliações, sendo 91 na categoria de cuidados intensivos (7,41\%), 75 na categoria de cu idados semi-intensivos $(6,11 \%)$. Houv e predominância de pacientes caracterizados por complexidade assistencial mínima $(44,38 \%)$ e intermediária $(22,15 \%)$, além de uma parcela significativa de pacientes de alta dependência para o serviço de enfermagem (19,95\%). 
A tabela 4 apresenta o númer o total de av aliações dos pacientes adultos e a frequência de distribuição de acordo com a pontuação por categoria e por grau de dependência e complexidade as sistencial no período de 30 dias no pronto-socorro, obtida p or meio da utilizaç ão do instrum ento de classificação de pac ientes d e Fugulin (2002).

Tabela 4 - Número total de avaliações dos pacientes adultos e frequência de distribuição de acordo com a pontuação por grau de dependência no período de 30 dias. São Paulo, 2009

\begin{tabular}{|c|c|c|}
\hline Complexidade Assistencial & Pontuação & $\mathbf{N}^{\circ}$ \\
\hline \multirow{6}{*}{ Mínimo } & 9 & 0 \\
\hline & 10 & 65 \\
\hline & 11 & 274 \\
\hline & 12 & 111 \\
\hline & 13 & 68 \\
\hline & 14 & 27 \\
\hline \multirow{6}{*}{ Intermediário } & 15 & 54 \\
\hline & 16 & 52 \\
\hline & 17 & 48 \\
\hline & 18 & 31 \\
\hline & 19 & 35 \\
\hline & 20 & 52 \\
\hline \multirow{6}{*}{ Alta Dependência } & 21 & 54 \\
\hline & 22 & 45 \\
\hline & 23 & 46 \\
\hline & 24 & 34 \\
\hline & 25 & 36 \\
\hline & 26 & 30 \\
\hline \multirow{5}{*}{ Semi-intensivo } & 27 & 17 \\
\hline & 28 & 19 \\
\hline & 29 & 12 \\
\hline & 30 & 16 \\
\hline & 31 & 11 \\
\hline \multirow{5}{*}{ Intensivo } & 32 & 5 \\
\hline & 33 & 8 \\
\hline & 34 & 20 \\
\hline & 35 & 58 \\
\hline & 36 & 0 \\
\hline TOTAL & & 1.228 \\
\hline
\end{tabular}


A tabela 4 mostra que, embora classifi cados dentro da mesma categoria em termos de grau de dependênc ia, os pac ientes pos suem pontuações diferentes, sendo que alguns $s$ e encontram em sit uações de limite entre as $c$ ategorias estabelecidas, isto é, pacientes cla ssificados em qualquer categoria, que se acrescido de um ponto em sua avaliação, passariam a ser classificados na categoria imediatamente superior ou o inv erso, caso haja a retirada de um ponto na avaliação haveria $\mathrm{m}$ udança para a categoria im ediatamente inferior em termos de necessidades assistenciais.

As mudanças de categorias de c uidados estabelecem maior ou menor carga de trabalho para a equipe de enfermagem, em função das horas de as sistência preconizadas pelo Conselho Federal de Enfermagem para cada uma delas conforme o artigo $5^{\circ}$ da Resolução COFEN No 293/2004 (COFEN, 2004):

- Pacientes de Cuidados intensivos - PClt: 17,9 horas de enfermagem (he)/cliente/24h;

- Pacientes de Cuidados semi-intensivos - PCSI: 9,4 he/cliente/24h;

- Pacientes de Cuidados intermediários - PCl: 5,6 he/cliente/24h e;

- Pacientes de Cuidados mínimos - PCM: 3,8 he/cliente/24h.

Do total de 1.228 avaliações rea lizadas, não verificamos pacientes classificados nas pontuações mínima (9 pontos) e máxima (36 pontos), 250 $(20,35 \%)$ ficaram em extremos de categori as isto é, pacient es cujas pontuações foram as máximas ou mínimas para a sua complexidade assistencial.

Dos 250 pacientes classificados nas extremidades das pontuações, 122 $(9,94 \%)$ estariam nos extremos que inte rferem na distribuição percentual de categorias, impactando na determinação qualitativa dos profissionais, de acordo com o artigo $5^{\circ}$ da Resolução COFEN No 293/2004 que estabelece para complexidade assistencial mínima e intermediária de 33 a 37\% dos profissionais de enfermagem devem ser Enfermeiros com o mínimo de seis, e os demais podem ser Auxiliares e/ou Técnicos de Enf ermagem; para comple xidade as sistencial semi-intensiva de 42 a $46 \%$ devem ser Enfermeiros e os demais, Técnicos e/ou Auxiliares de 
Enfermagem e; para complexi dade assistencial intensiva de 52 a $56 \%$ devem ser Enfermeiros e os demais Técnicos de Enfermagem.

Desta forma foram classificados 52 pac ientes com a pontuação máxima para cuidados intermediários (20 pontos), 54 com a pontuação mínima para categoria alta dependência (21 pontos) a qua I pela mesm a Resolução faz parte da categoria de cuidados s emi-intensivos que também te ve 11 pac ientes clas sificados c om 31 pontos que é a pontuação $\mathrm{m}$ áxima par a es ta complexidade assistencial e 5 pacientes com a pontuação mínima para cuidados intensivos (32 pontos).

A tabela 5 apresenta a distribuição, em números absolutos e percentuais, das avaliações dos pacientes adult os, por unidade de internação e por categoria de cuidados ou complexidade assistencial do Pronto-so corro, de acordo com o instrumento de classificação de pacientes de Fugulin (2002) no período de 30 dias.

Tabela 5 - Número total de avaliações dos $p$ acientes ad ultos distribuídos por unidade de internação no Pronto-socorro no período de 30 dias. São Paulo, 2009

\begin{tabular}{lccccccc}
\hline & Intensivo & $\begin{array}{c}\text { Semi- } \\
\text { intensivo }\end{array}$ & $\begin{array}{c}\text { Alta } \\
\text { dependência }\end{array}$ & Intermediário Mínimo & Total (Unidade) & $\%$ \\
\hline Emergência & 91 & 71 & 126 & 56 & 28 & 372 & 30,29 \\
$\begin{array}{l}\text { Observação } \\
\text { Masculina }\end{array}$ & 0 & 4 & 70 & 148 & 334 & 556 & 45,28 \\
$\begin{array}{l}\text { Observação } \\
\text { Feminina }\end{array}$ & 0 & 0 & 49 & 68 & 183 & 300 & 24,43 \\
\hline $\begin{array}{l}\text { Total } \\
\text { (Complexidade }\end{array}$ & 91 & 75245272 & & 545 & 1.228 & 100,00 \\
\hline Assistencial) & & & & & & & \\
\hline
\end{tabular}

Por meio dos dados, verificamos que $100 \%$ dos pacientes com necessidades de cuidados intensivos (91 pacientes), estavam na unidade de emergência, além de 71 pacientes com necessidades de cuidados semi-intensivos, 126 pacientes com alta dependência, 56 pacientes de cuida dos intermediários e 28 pacientes de cuidados mínimos.

Na unidade de observação masculina, foram avaliados 334 pacientes de cuidados mínimos, 148 de cuidados inte rmediários, 70 com alta dependência da 
equipe de enfermagem e quatro com necessi dade de cuidados se mi-intensivos. $\mathrm{Na}$ unidade de observação feminina, foram av aliados 183 pacientes de cuidados mínimos, 68 de cuidados intermediários e 49 com alt a dependência da equipe de enfermagem.

Chama a atenção a concentração de pacientes c om alta dependência, estáveis sob o ponto de vista clínico por ém com total dependência da equipe de enfermagem para o atendimento das neces sidades humanas básicas na unidade de pronto-socorro.

O Conselho Federal de Enfermagem util izou o Sistema de Classificação de Pacientes adaptado de Fugulin et al (1994) como parâmetro para o dimensionamento de pess oal de enfermagem nas in stituições de saúde, inicialmente, a partir da publicação da Resolução COFEN Nº 189/96 (COFEN, 1996).

Em 2004, o Conselho Federal de En fermagem revogou a Res olução COFEN NN 189/96 por meio da pub licação da Res olução CO FEN NN293/2004, que fixa e estabelece parâmetros para o dimens ionamento do quadro de profissionais de enfermagem nas unidades assistenciais das instituições de saúde e assemelhados.

A metodologia proposta em 2004, manteve a utili zação do sistema de classificação de pacientes adaptado de Fugulin et al (1994), como parâmetro para a determinação do grau de dependência dos pacientes em relação à equipe de enfermagem. Entretanto, como na Reso lução COFEN Nº 189/ 96, a Nº 293/2004 também não considera a categoria alta dependência e recomenda que os pacientes que porventura estejam classific ados nessa categoria de cuidados sejam agrupados com os da categoria de cuidado semi-intensivo.

Dessa forma, a Resolução COFEN N 293/2004 estabelece quatro categorias de cuidados a seguir:

- Pacientes de Cuidados mínimos: estáve is sob o ponto de vista clínico e de enfermagem e autossuficientes quant $\mathrm{O}$ ao atendimento das necessidades humanas básicas;

- Pacientes de Cuidados in termediários: estáveis sob o ponto de vista clínico e de enfermagem, requerendo avaliações médicas e de enfermagem, com parcial 
dependência dos profissionais de enf ermagem para o at endimento das necessidades humanas básicas;

- Pacientes de Cuidados Semi-intensivos : recuperáveis, sem risco iminent e de morte, passíveis de instabilidade das $f$ unções vitais, requerendo assistência de enfermagem e médica permanente e especializada e;

- Pacientes de Cuidados intens ivos: grav es e recuper áveis, com risco iminente de morte, sujeitos à inst abilidade das funções vitais, necessitam de assistência de enfermagem e médica permanente e especializada.

Desse modo, a frequência de distribui ção do núm ero total de avaliações quanto a c omplexidade assistencial dos pacientes adultos no mês de janeiro de 2009 no pronto-socorro em conformidade com a Resolução COFEN Nº 293/2004 que cons idera somente quatro categoria s de com plexidade a ssistencial para a determinação do nível de at enção requerida pelas c ondições de saúde em que o paciente s e encontra, por meio da utiliz ação do Sistema de Classific ação de Pacientes adaptado de Fugulin et al (1994), está apresentada na tabela 6.

Tabela 6. Número total de avaliações dos $p$ acientes ad ultos e freq uência de $d$ istribuição quanto ao g rau de dep endência assistencial $\mathrm{n}$ o período d e 30 dias $\mathrm{n}$ o Pronto-socorro, de acordo com a Resolução COFEN Nº 293/2004. São Paulo, 2009

\begin{tabular}{lcr}
\hline Complexidade Assistencial & $\mathrm{N}^{\circ}$ & $\%$ \\
\hline Intensivo & 91 & 7,41 \\
Semi-intensivo & 320 & 26,06 \\
Intermediário & 272 & 22,15 \\
Mínimo & 545 & 44,38 \\
\hline Total 1.228 & & 100,00 \\
\hline
\end{tabular}

A tabela 6 demonstra os números de avaliações por complexidade assistencial, de acordo com a Resolução COFEN N² 293/2004. Os dados referentes às complexidades as sistenciais intensivas, intermediária s e mínimas são iguais à 
tabela 3, que cons idera cinc o categorias. A diferença fica por conta dos dados referentes à categoria semi-intensiva que passou de 75 para 320 avaliaç ões por conta da alta dependência ser incluída nesta categoria.

\subsection{DISCUSSÃO DOS DADOS}

A partir dos dados coletados no setor de estatística da instituição de saúde onde foi realizada a pesquisa, denominado Serviço de Prontuário do Pac iente e por meio do número total de instrumentos de classificação de pacientes obtidos, verificamos um número maior do que a $\mathrm{m}$ édia mensal de internações regist rada no ano de 2008.

Tal fato poderia ser considerado como ocorrência em um mês atípico no pronto-socorro, porém ao obs ervarmos os números médios mensais do ano de 2007, constatamos uma média mensal menor que do ano de 2008 , o que demonstra uma variação significativa no número de internações nessa unidade.

Verifica-se, por meio do número médi o mensal de atendimentos realizados, que a maioria dos usuários do pronto-soco rro não necessita de int ernação, mas são atraídos para esse serviço em busca de consultas de rotinas.

Esse grande número de atendimentos no pronto-socorro, mesmo que não haja a efetivação da internação, acaba por sobrecarregar a unidade e a equipe multiprofissional que atua ne sse serviço, incluindo a equ ipe de enfermagem pela existência de um grande número de pacientes que mesmo não internados, requerem assistência de enfermagem. Temos como exemplo os que são atendidos nas salas de sutura, procedimentos ambulatoriais, sa la de administração de medicaç ões, sala de inalação, encaminhamentos e orientações nas dep endências da unidade para a realização de exames laboratoriais e de imagens.

No período de coleta dos dados, foram realizadas 1.228 avaliaç ões aos pacientes internados nas unidades de em ergência e observação do pronto- socorro, uma média de 40,93 pacientes avaliados por dia. Es se valor representa uma taxa de ocupação média de $20,38 \%$ acima da previsão dos leitos oficiais disponíveis. 
Esse percentual exc edente representa a operacionalização dos leitos ext ras por meio de macas pelos corredores, o que torna a planta física inadequada para os pacientes que se s ubmetem a condições insatisfatórias, uma vez que ficam acomodados em locais de gr ande circulação de pess oas, altos índices de $r$ uídos e luminosidade constante e, para a equi pe multiprofissional, que necessita desenvolver seu processo de trabalho em loca is inapropriados para a realização de técnicas específicas (visitas, coleta de informações, procedim entos, exame físico, etc).

Para a equipe de enfermagem, as condições inadequadas de trabalho se traduzem pela necessidade de realização de deslocamentos maiores. Isso em razão de os corredores não terem si do projetados para alojar pacientes e muito menos para a realização de procedime ntos, porque ficam afastados de locais como salas de procedimentos, pontos de oxigênio para inalação, vácuo para aspiração, posto de enfermagem para o prepar o de medicamentos, entre $t$ antas outras atividades de enfermagem que necessitam de materiais e equipamentos.

De acordo com o estudo de Scapim, Tiveron e Marvulo (2007), essas demandas dificultam o trabalho dos profiss ionais que des envolvem suas atividades em condiç ões inadequadas, gerando a nec essidade de uma reflexão sobre o processo de trabalho da equipe e uma $r$ eadequação da estrutura física da unidade para não comprometer a qualidade da a ssistência de enfer magem prestada à população.

As características dos atendim entos assemelham-se aos identificados por Puccini e Cornetta (2008). Esses autores realizaram estudo de ocorrências no pronto-socorro central do município de It apecerica da Serra par a o monitoramento de eventos sentinela para a atenção bási ca. Constataram alta proporção de pessoas c om problemas de saúde que se avaliavam como passíveis de serem resolvidos mais apropriadamente em unidades básicas de saúde, mas que demonstravam desc onfiança em relaçã o ao atendimento naque les serviços, sinalizando anseio pelos recursos tecnológi cos disponibilizados e a sensação de resolubilidade, pois realiz avam vários exames e eram medicados "na hora" no pronto-socorro. 
Também para Souza et al. (2007), o acesso irrestrito e o número excessivo de pacientes nos pronto-socorros podem ter como uma das causas a alta inc idência de usuários que buscam atendimento imediato para problemas simp les, criando uma sobrecarga para a equipe médica e de enfermagem. Essa sobrecarga é considerada um dos fatores de risco para o desenvolvi mento de eventos adversos, sinalizando a ocorrência de falhas relacionadas à s egurança e à qualidade da assistência prestada aos pacientes.

Os dados obtidos também corroboram o relatório do Projeto "Avaliaç ão das Organizações Sociais de Saúde OSS/São P aulo" (Convênio Sec retaria Estadual da Saúde de São Paulo/Universidade de São Paulo - Faculdade de Saúde Pública) que realizou estudo do perfil da demanda do serviço de pronto-socorro do Hospital Geral do Itaim Paulista. Constataram que a maioria dos atendimentos de pronto-socorro do referido hospital não abrangia caso s de urgênc ia ou emergência e que tais atendimentos deveriam ser abs orvidos pela rede ambulatorial básic a da região (Yamada et al, 2002). haja visto que o perc entual de pacientes classificados nas categorias de cuidados intermediários e mín imo: $66,53 \%$ do total de pacientes internados e, principalm ente pelo elevado número de atendimentos realiz ados no pronto-socorro em relação ao número de internações efetivadas.

O estudo não teve como objetivo a cara cterização dos pacientes em relação às patologias apresentadas, porém, duran te a coleta dos dados, notou-se a presença constante e significativ a de pacient es psiquiátricos. Tal fato se deve, de acordo com Martins (2007), à fragilidade e ineficác ia do sistema e dos recursos extra-hospitalares, levando ess es pacient es ao trajeto "casa - pronto-socorro hospital" por apresentarem episódios ag udos e gr aves de transtornos mentais variados que muitas vezes não possuem ro tinas controláveis. De acordo com o autor, o instrumento de c lassificação de pacientes de Fugul in não traduz as condições apresentadas e a complexi dade ass istencial dos pacientes com transtornos mentais, pois eles não têm sensibilidade para det erminar o nível de dependência da enfermagem psiquiátrica, tornando-se difícil quantificar a assistência a esses pacientes.

Embora os pacientes psiquiátric os não apr esentem problemas c línicos que demandem assistência de enfermagem cons tante do ponto de vista da satisfação 
das neces sidades humanas básicas, há a necessidade de uma observação constante em função da inst abilidade de humor e dos eventos associados à própria patologia psiquiátrica, podendo apresentar episódios de auto e hetero agressividade, tentativas de fuga e suicídio, entre outras intercorrências comuns a esses pacientes, colocando em risco a seguranç a dos us uários do pronto-socorro que não estão internados, dos que estão internados, dos próprios pacientes psiquiátricos e dos profissionais envolvidos na assistência.

Mudanças na complexidade assistencia I interferem na carga de trabalho, portanto, devemos estar atentos para verificar se não houve alteração nas condições dos pacientes com conseqüente variação do grau de dependência em relação à assistência da equipe de enfermagem.

A complexidade assistencial relaciona o grau de necessidade do paciente, por meio do $v$ olume e da intensidade de consumo de recursos, durante a assistência prestada. $\mathrm{O}$ acompanhamento da complexidade ass istencial durante o período de internação permite identificar as atividades e procedim entos executados e o tempo consumido pela equipe de enf ermagem, $c$ ontribuindo para o planejamento mais racional das ações a serem implementadas com os pacient es. De acordo com os autores, durante o período de internação, os pacientes podem permanecer classificados na mesma categoria de cuidado que foram admitidos, porém podem aumentar ou diminuir seu grau de complexi dade assistencial em relação à demanda de pessoal de enfermagem. (ARAÚJO, PERROCA e JERICÓ, 2009)

Nesse sentido, os resultados obt idos indicam a necessidade de uma constante e competente avaliação, por parte dos enfermeiros do pronto-socorro, dos pacientes internados para que não haja interferência nas variáveis envolvidas no dimensionamento de pessoal de enferm agem, principalmente nas situações limítrofes. Vale pontuar que 52 pacientes da categoria de cuidados intermediários encontram-se no limit e máximo para essa categoria (20 pontos), 54 pacientes da categoria alta dependência situam-se no limite mínimo para essa categoria (21 pontos), 11 pacientes da categoria semi -intensiva enquadram-s e no limit e máximo para essa categoria (31 pontos) e cinco pa cientes foram classificados na pontuação mínima para a categoria cuidados intensivos (32 pontos). 
Isso significa que pode-se ter uma variaç ão significativa entre as categorias de cuidados com o acréscimo ou a retirada de apenas um ponto da classificação em função da avaliaç ão realiz ada pelos enfermeiros, podendo interferir substancialmente no cálculo do pessoal de enfermagem.

Araújo, Perroca e Jericó (2009) rea lizaram estudo da variabilidade do grau de complexidade assistencial do pacient e em relação à equipe de enfermagem. Constataram que as transições não oco rrem necessariamente de forma ordenada e que os pacientes podem $\mathrm{m}$ udar para uma categoria de complexidade assistencial imediatamente acima ou abaixo daquela em que se encontram. Vê-se que esse trânsito não constitui necessariamente uma regra.

Outro fator a se destacar é a grande qua ntidade de pacientes classificados como de alta dependência para a assistênc ia de enfermagem $(10,26 \%)$ na unidade de emergência, uma vez que essa unidade, de acordo com a definição do Ministério da Saúde, é destinada à ass istência de doentes, com ou sem ris co de vida, e cujos agravos à saúde necessitam de atendim ento im ediato (BRASI L, 1987). Essa permanência signific a que o pessoal de enfermagem presta assistência característica de unidades de int ernação em decorrência da pr esença de pacientes internados que deveriam ser encaminhados para outras unidades.

Quando ut ilizamos a metodolo gia prop osta pela Resoluçã o COFEN Nº 293/2004 para a determinação da complexi dade assistencial dos pacientes, que não considera a categoria dos pacientes com complexidade as sistencial de alta dependência para a assistência de enfermagem, obtivemos um aumento percentual significativo do total das avaliações de pa cientes dentro da categoria de cuidados semi-intensivos. A categoria semi-intensiv a passa de 75 pacientes, percentual de $6,11 \%$, para 320 pac ientes representando $26,05 \%$ do total de avaliações. Esse percentual não representa na realidade o perf il assistencial da clientela, pois agrupa pacientes com características diferentes em termos assistenciais, já que a alta dependência em relação à equi pe de enfermagem está diretamente relacionada à dependência e neces sidade de assistência de enfermagem e não à inst abilidade hemodinâmica e a cuidados médicos permanentes. 
O aglutinamento das categorias, se mi-intensiva c om alta dependência, conforme preconizado pela Resoluçã o COFEN N²293/2004, estabelece uma mudança no dimens ionamento da equipe de enfermagem, não só em termos quantitativos, mas também em termos qualitativos, pois estabelece um percentual de enfermeiros maior em relação ao número de técnicos ou auxiliares de enfermagem. 
Considerações finais 


\section{CONSIDERAÇÕES FINAIS}

O estudo permitiu estabelecer a caract erização do perfil ass istencial da clientela adulta internada na unidade de em ergência e nas observações masculina e feminina do pronto-socorro do Hospital Geral do Itaim Paulista.

Foram realizadas 1.228 avaliaç ões co $\mathrm{m}$ o instrumento de clas sificação de pacientes de Fugulin (2002), resultando numa média diária de 40,93 pacientes/dia, sendo: 3,03 pacientes de cuidados intens ivos; 10,67 pacientes de cuidados semiintensivos; 9,07 pacientes de cuidados intermediários e 18,16 pacientes de cuidados mínimos, já considerando a cat egoria de cuidados $\mathrm{s}$ emi-intensivos junto com a categoria de alta dependênc ia para a equipe de enfermagem como estabelece a Resolução COFEN nº 293/2004.

A caracterização da clientela atendida no pronto-socorro fornece subsídios para o estabelecimento e o gerenciame nto das necessidades de pessoal de enfermagem da unidade como uma das variáveis envolvidas nesse processo, porém, não é o suficiente para que i sso seja efetivado, posto que o dimensionamento de pessoal envolve out ras variáveis que não foram verificadas. Faz-se necessário, portanto, a identificação das horas efetivas de trabalho da equipe de enfermagem, em função da realidade in stitucional e tam bém do índice de absenteísmo.

Além diss $\mathrm{o}$, os dados referentes à demanda no pronto-socorro permitem verificar que é elevado o número de atendi mentos de pacientes que não necessitam de internação ou obs ervação, levando à conclusão de que poderiam ser atendidos em outros serviços da atenção primária ou em serviços como o Atendimento Médico Ambulatorial (AMA), além de uma maioria de pacient es internados com necessidades de cuidados mínimos e interm ediários, principalm ente nas unidades de observação.

Também foram verificados pacientes com necessidades de cuidados mínimos e intermediários na uni dade de emergência, o que descaracteriza o tipo de assistência que deve ser prestada naquela unidade. 
Diante de tais constatações, delineia- se a necessidade de uma revisão do processo de trabalho da equipe de enferm agem para a adequação a essa realidade vivenciada, uma vez que a neces sidade assistencial dos pacientes e a qualidade da oferta dos serviços para suprir essas demandas são reais.

A readequação da planta física da unidade é um fator imprescindível par a uma assistência adequada ao paciente, a fim de proporci onar maior conforto e dignidade àqueles que precisam de assistência, além de melhor ar a produtividade dos profissionais envolvidos.

A constatação de que há um grande contingente de pacientes da psiquiatria à espera de vagas para internação em unidade especiali zada ou em outras instituições requer da equipe de enfermagem, uma assist ência diferenciada e um local apropriado para a observaç ão constante e princ ipalmente para a manut enção da integridade física desses pacientes no pronto-socorro, bem como das pessoas que circulam pela unidade.

O número elevado de atendimentos em relação ao número de internações e a operacionalização de leitos extras nos corredores reflete a ausência de um serviço de regulação do fluxo do pronto-socorro que garanta a universalização do acesso ao serviço de saúde, princípio do Sistem a Único de Saúde. O acolhimento desses pacientes não garante que a qualidade do at endimento seja assegurada, pois fic a clara a inadequação das condições a que são submetidos pacientes e profissionais.

A regulação do fluxo para a diminuiç ão de atendiment os não nec essários no pronto-socorro requer mudanças culturai $s$ da própria populaç ão e uma definição clara de conceitos de urgência e emergência e uma melhora no acesso aos serviços da atenção básica já iniciada com o progr ama de saúde da família . Desse modo, o hospital e principalmente o pronto-socorro funcionaria somente como a referência para os serviços de menor complexidade.

A partir dos resultados deste estudo pretende-se por meio da realidade vivenciada no pront o-socorro, conscientiz ar os enfermeiros que a utilização do sistema de classificação de pacientes é um instrumento para a gestão da unidade, fornecendo dados para alocação mais eficiente dos recursos humanos disponíveis e para a determinação das necessidades de readequação do processo de trabalho. 
A caracterização do perfil assistencial nã o é o suficiente para a realizaç ão do dimensionamento das necessi dades quantitativas e qual itativas de pes soal de enfermagem, mas é o princípio para a implementação de uma metodologia científica para a realização desse planejamento por parte do enfermeiro, fornecendo subsídios técnicos para a discussão das necessi dades de pess oal da unidade, eliminando o empirismo e aumentando o repertório de argum entos frente ao gestor da instituição visando a melhoria da qualidade da assistência de enfermagem. 
Referências 


\section{REFERÊNCIAS}

ALWARD,R.R. Patient classifi cation systems: the ideal v s. reality. J. Nurs. Adm., v. 13, n.2, p.14-9, 1983.

ANTUNES, A.V.; COSTA, M.N. Dimensionamento de pessoal de enfermagem em u m hospital un iversitário. Rev. Latino-Am. Enferma gem. Ribeirão Preto, v. 11, n. 6, p.832-9, 2003.

ARAÚJO, V.B. de; PERROCA, M.G.; JERI CÓ, M.de C. Variab ilidade do grau de complexidade assistencial do paciente em relação à equipe de enfermagem. Rev. LatinoAm. Enfermagem, Ribeirão Preto, v.17, n.1, p 29-34, jan-fev, 2009.

AWADA, S. B.; REZENDE, W.W. Serviços de emergência: problema de saúde pública. In. MARTINS, H.S. et al. Pronto socorro: condutas do Hospital das Clínicas da Faculdade de Medicina da Universidade de São Paulo. Barueri: Manole, 2007.

BISENG, W. Administração financeira em engenharia clínica. São Paulo; 1996.

BITTAR, O. J. N. V. Di stribuição d os recursos humanos em oito hospitais gerais de São Paulo. Rev Panam Salud Publica. Washington, v. 2, n. 1, 1997. Dispon ível em: <http://www.scielosp.org/pdf >Acesso em: 11 Abr 2007.

BOCHEMBUZIO, L.; GAIDZINSKI, R.R. Instru mento para classificação de recém-nascido s de acordo com o grau de dependência de cu idados de enf ermagem. Acta Paul. Enferm., v.18, n.4, p.382-9, 2005.

BORDIN, L .C. Distribuição do tempo das enfermeiras: identificação e análise em unidade médico-cirúrgica. 2008, 166 f. Dissertação de mestrado. EEUSP, São Paulo.

BRASIL. Ministério da Saúde. Secretaria Nacional de Org anização e Desenvolvimento de Serviços de Saúde. Terminologia básica em saúde. Brasília: Centro de Docume ntação do Ministério da Saúde, 47 p., 1987. (Série B: Textos básicos de saúde, 4). Disponível em: $<$ http://bvsms.saude.gov.br/bvs/publicacoes/0112terminologia1.pdf> acesso em 04/06/09.

BRASIL. Lei $\mathbf{n}^{\circ}$ 7.498, de 25 de junho de 1986. Dispõe sobre a regulamentação do exercício da Enfermagem e dá o utras providências. In: CONSELHO REGIONAL DE E NFERMAGEM DE SÃO PAULO. Doc umentos básicos de en fermagem: enfermeiros, técnicos, a uxiliares. São Paulo, 2001, p.36-41. 
BRASIL. Ministério da Saúde. Conselho Nacio nal de Saúde. Resolução n. 196, de 10 de outubro de 1996, art. 4 . Consentimento Livre e Esclarecido. Brasília, DF, 1996.

BRASIL. Portaria no 2048 de 05 de Novembro de 2002, que estabelece os prin cípios e diretrizes dos siste mas estad uais de urgência e emergência. Disponí vel em: <http://dtr2001.saude.gov.br/samu/legislacao/leg 2048.htm> acesso e m 03 de agosto de 2006.

CAMPEDELLI, M.C.; TAKITO, C.; SANCINETTI, T.R.; BENKO, M.A. Cálculo de pe ssoal de enfermagem: competência da enfermeira. Rev Bras. Enferm. Brasília, v. 41, n. 3/4, p.199204, jul-dez, 1988.

CARNEIRO JUNIOR, N. O setor público não estatal: as organizações sociais como possibilidades e limites na gestão pública de saúde.2002, 242 f. Tese de do utorado, FMUSP, São Paulo.

CHENSO, M.Z.B.; HADDAD, M. do C.L.; SÊCCO, I.A.de O., DORIGÃO, A. M.; NISHIYAMA, M.N. Cálculo de pessoal de enfermagem e m hospital universitário do Paraná: uma proposta de adequação. Semina: Ciências Biológicas e da Saúde, Londrina, v.25, p. 81 -92, jandez, 2004.

CHIAVENATO, I. Recursos humanos. 7 ed. São Paulo : Atlas, 2002.

CONSELHO FEDE RAL DE EN FERMAGEM. Resolução COFEN 189/96. Estabelece parâmetros para o dimensionamento do qu adro de profissiona is de Enferma gem nas unidades assistenciais d as instituições. In: Conselho Federal de Enfermagem. Docu mentos básicos de Enfermagem. Principais leis e resoluções que regulamentam.

CONSELHO FEDERA L DE ENFERMAGEM. Resolução COFEN 293/2004. Estabelece parâmetros para o dimensionamento do qu adro de profissiona is de Enferma gem nas unidades assistenciais $d$ as instituições de saúde e assemelhados. In: Conselho Federal de Enfermagem. Docume ntos básico s de Enfer magem. Pri ncipais leis e reso luções que regulamentam.

DAL PAI D.; LAUTERT L. Suporte humanizado no Pron to Socorro: um desafi o para a enfermagem. Rev. Bras. Enferm, v.58, n.2, p.231-4, 2005. Disponível e m < http://www.scielo.br/pdf/reben/v58n2/a21.pdf f > acesso em 04/06/09 
FARIAS, F. A.C. Dimensionamento de pessoal de enfermagem para pronto-socorro especializado em afecções cardiovasculares. 2003, 257 f. Tese de doutorado, EEUSP, São Paulo.

FUGULIN, F.M.T. et al. Implantação do sistema de classificação de pacientes na unidade de clínica médica do Hospital Universitário da Universidade de São Paulo. Rev.Méd. HU-USP, v.4, n. 1 / 2, p.63-8, 1994.

FUGULIN, F.M.T. Sistema de classificação de pacientes: análise da $\mathrm{s} h$ oras de assistência de enfermagem. 1997, 81 f. Dissertação de mestrado, EEUSP, São Paulo.

FUGULIN, F.M.T. Dimensionamento de pessoal de enfermagem: Avaliação do quadro de pessoal de enfermagem das unidades de internação de um hospital de ensino. 2002, Tese de doutorado, EEUSP, São Paulo.

FUGULIN, F.M.T.; $\quad$ GAIDZINSKI, R.R.; $\quad$ KURCGANT, P. Sistema $\quad$ de classificação de pacientes: identificação do perfil assistencial d os pacientes das unida des de inter nação do HU-USP. Rev latino-am enfermagem, Ribeirão Preto, v.13, n.1, p.72-8, 2005.

GAIDZINSKI, R.R. O dimensionamento de pessoal de enfermagem segundo a percepção de enfermeiras que vivenciam essa prática, 1994, 258 f. Tese de Doutorado, EEUSP, São Paulo.

GAIDZINSKI, R.R. Dimensionamento de pessoal de enfermagem em instituições hospitalares. 1998. 119 f. Tese (Livre-docência), EEUSP, São Paulo.

GAIDZINSKI, R.R; SANNA, M. C.; LEITE, M.M.J.; MAYOR, E.R.C. Estudo das ausências da equipe de enfermagem nu $\mathrm{m}$ hospital geral de grande porte. Rev. Enferm. Complexo HC/FMUSP, v.1, n.4, p.8-14, 1998.

GAIDZINSKI, R.R; FU GULIN, F. M.T.; CAST ILHO, V. Dimensionamento de pessoal de enfermagem em instit uições de saúde. In. KURC GANT, P. (coord.) . Gerenciamento em enfermagem. Rio de Janeiro: Guanabara Koogan, 2005.

GARCIA, E. de A. Distribuição do tempo de trabalho das enfermeiras em unidade de emergência. 2009. 145 f. Dissertação de mestrado, EEUSP, São Paulo.

GIL, A.C. Como elaborar projetos de pesquisa. 4 ed. São Paulo : Atlas, 2002.

HORTA, W. de A. Processo de enfermagem, São Paulo: EPU - EDUSP, 1979. 
JUNG .G, OLIVEIRA A., CORRAL S. Documentar a implantação do Therapeutic Intervention Scoring System - TISS no Serviço de Emergên cia do Hospital Mãe de Deus. Enfermagem Atual; v. 3, n.13, p.27-31, 2003.

MADALOSSO, A.R.M. latrogenia do cuidado d e enfermag em: dialogando com o perigo no quotidiano profissiona I. Rev.latino-am.enfermagem, Ribeirão Preto, v. 8, n. 3, p. 11-7, julho, 2000.

MARTINS, E.A.P.; HADDAD, M.do C.L. Validação de um instrume nto que cla ssifica os pacientes e m quatro graus de de pendência do cuidado de enfermagem. Rev.latinoam.enfermagem, v.8, n.2, Ribeirão Preto, Abril, 2000.

MARTINS, P.A.S.F. Si stema de c lassificação de pacientes na enfermagem psiquiátrica: validação clinica. 2007, 123 f. Tese de doutorado. EEUSP, São Paulo.

MELLO, M .C. Estudo do tempo no trabalho da enfermagem: construção de instrumento de classificação de atividades para implantação do método amostragem do trabalho. 2002, 154 f. Dissertação de mestrado. EEUSP, São Paulo.

MENZANI, G. Stress entre enfermeiros brasileiros que atuam em pronto-socorro. 2006, 112 f. Dissertação de mestrado. EEUSP, São Paulo.

MONTEZELI, J.H.; LOPES, A.de A. Implantação de um sistema classif icatório do grau de dependência dos cuidados de enferm agem em um serviço de emergência. Cogitare Enferm. Curitiba, v. 11, n. 3, p. 239-44, set-dez, 2006.

NICOLA, A .L. Dimensionamento de pessoal de enfermagem no hospital universitário do oeste do Paraná. 2004, 153 f. Tese de Doutorado, EERP-USP, Ribeirão Preto.

ORGANIZAÇÃO NACI ONAL DE ACRE DITAÇÃO - ONA. Serviços acreditado s / serviços hospitalares / Acreditado pleno. Disponível em

<http://www.ona.org.br/site/internal institucional.jsp?p.offset=10\&id=2\&Qualification=2> acesso em 12/06/2009.

PERROCA, M .G. Instrumento de classificação de pacientes de Perroca: validaçã o clínica. 2000, 156 f. Tese de doutorado, EEUSP, São Paulo.

PERROCA, M.G.; GAIDZINSKI, R.R. Avaliand o a confia bilidade interavaliadores de um instrumento para classif icação de p acientes - coeficiente kappa. Rev. Esc. Enferm. USP, São Paulo, v. 37, n.1, p. 72-80, 2003. 
PICCHIAI, D. Dimensionamento quantitativo de recursos $h$ umanos em hospitais pr ivados e públicos no Estado de São Paulo. EAESPIFGV - núcleo de pesquisas e publicações, relatório de pesquisa $n^{\circ}$ 9/2000. Disponível em: <http://www.eaesp.fgvsp.br> acesso em 16/04/2007.

POLIT, D.F., HUNGLER, B.P. Fundamentos de pesquisa em enfermagem, 3 ed. Port o Alegre: Artes Médicas, 1995.

PUCCINI, P. de T., CORNETTA, V . K. Ocorrê ncias em pronto-socorro: eventos sentinela para o monitoramento da atenção básica de saúde. Cad. Saúde Pública, Rio de Janeiro, v. 24, n.9, p.2032-42, set, 2008.

RIBEIRO, C.M. Sistema de classificação de pacientes como subsídio para provimento de pessoal de enfermagem. 1972, 98 f. Tese de Doutorado, EEUSP, São Paulo.

RODRIGUES FILHO, J. Sistema de classificaçã o de pacien tes - Parte I: Dimensionamento de pessoal de enfermagem. Rev. Esc. Enferm. USP, São Paulo, v.26, n.3, p.395-404, 1992.

SANTA MARCELINA. Hospital Geral do Itaim Paulista. OSS Santa Marcelina. Serviço de prontuário de paciente. São Paulo, 2008.

SANTA MARCELINA. Hospital Geral do Itaim P aulista. OSS Santa Marcelina. Serviço de prontuário de paciente. São Paulo, 2009.

SANTA MARCELINA. Hospital Santa Marcelina: Projetos sociais. Parceiros na saúde; 2009. Disponível em: <http://www.santamarcelina.org/sm/obras.asp> acesso em 12/06/2009.

SÃO PAULO. Secretaria municipal da saúde. Estatística s/ Disponível em: <http://portal.prefeitura.sp.gov.br/secretarias/saude/tabnet> acesso em_04/06/09.

SCAPIM, E .P.; TIVERON, E. R.; MARVULO, M.M.L. Di mensionamento de pessoal d e enfermagem em uma unidade de observação de um pronto-socorro. Revista Nursing, São Paulo, v.10, n.112, p.412-8, 2007.

SOUZA, R.B.; SILVA, M.J.P.; NORI, A. Pronto-Socorro: uma visão sobre a int eração entre profissionais de enfermagem e pacientes. Revista Gaúcha de Enfermagem, Porto Alegre, v.28, n.2, p.242-9, 2007.

TANAKA, O.Y.; MELO, C. Avaliação de programas de saúde do adolescente: um modo de fazer. 1. ed., São Paulo: EDUSP, 2004. 
TRANQUITELLI, A.M.; PADILHA, K.G. Sist emas de classif icação de pacien tes como instrumentos de gestão em unidades de terap ia intensiva. Rev. Esc. Enferm. USP. São Paulo, v.41, n.1, p.141-6, 2007.

VEIGA, K.C.G. latrog enia de enfermagem em unidade de emergência. Rev. Baiana Enfermagem, Salvador, v. 8, n. 1/2, p. 68-101, 1995.

YAMADA, A. T., et al. Subprojeto Análise da demanda. Relatório do estudo do perfil da demanda do serviço de pronto socorro do Hospital Geral de Itaim Paulista. In: Castro Sá, E.N. de. Gomes, M.C. (Coord.). Projeto Avaliação das Organizações Sociais de Saúde OSS/São Paulo (Con vênio SES - SP/USP- FSP), Fa culdade de Saúde Pública da Universidade de São Paulo, 78 p., 2002. 
Apêndices 


\section{APÊNDICE 1}

Solicitação de autorização institucional para realização de estudo

Ilmo(a).Sr(a).Diretor(a) do Hospital

Prezado(a) senhor(a)

Eu, Renato Ohara, enfermeiro, aluno regu larmente matriculado no Programa de Pós Graduação em Enfermagem Fundament al - nível mestrado, da Escola de Enfermagem de Ribeirão Preto da Universi dade de São Paulo, s ob a or ientação da Profa Dra Márcia Regina Antonietto da Costa Melo, venho solic itar a V.Sa., autorização para realização do projeto de pesqui sa i ntitulado "Caracterização do perfil assis tencial da clientela de um pronto-socorro", cujo objetivo é caracterizar o perfil assis tencial dos client es adultos internados na uni dade de pronto-socorro de um hospital geral como um dos subsídios para o dimensionamento do pessoal de enfermagem. Solicito autorização para des envolver o estudo nessa instituição, em especial na Unidade de Pronto-socorro que utilizará um instrumento de classificação de pacientes em anexo.

Desde já agradecemos sua atenção e colocamo-nos à disposição para outros esclarecimentos que se façam necessários.

São Paulo, SP de de 2008

\section{Renato Ohara}

F: (11)2511-8930 Cel: 8589-4134

e-mail: renatoeerp@usp.br 


\begin{abstract}
APÊNDICE 2
Caracterização da Unidade caso

(Dados coletados no setor de registros estatísticos da instituição)
\end{abstract}

Leitos de observação adulto no Pronto-socorro

Leitos na sala de emergência adulto

Média mensal de atendimentos - Geral

Média mensal de atendimentos - Pronto-socorro adulto

Média mensal de internações - Geral

Média mensal de internações no último ano - Pronto-socorro adulto 


\section{APÊNDICE 3}

Caracterização da Unidade Caso em relação ao número total de profissionais de enfermagem para as 24 horas do dia

(Dados coletados no Departamento de Enfermagem)

$N^{\circ}$ de enfermeiros no pronto-socorro

$N^{\circ}$ de técnicos de enfermagem no pronto-socorro

$\mathrm{N}^{\circ}$ de auxiliares de enfermagem no pronto-socorro 


\section{APÊNDICE 4}

\section{TERMO DE CONSENTIMENTO LIVRE E ESCLARECIDO}

\section{Título do projeto: CARACTERIZAÇÃO DO PERFIL ASSISTENCIAL DA CLIENTELA DE UM PRONTO-SOCORRO}

Eu, Renato Ohara, enfermeiro, aluno de pós- graduação da Escola de Enfermagem de Ribeirão Preto-USP, re sponsável por esta pesquisa, sob orientação da Prof ${ }^{a} \operatorname{Dr}^{\mathrm{a}}$ Márcia Regina Antonietto da Costa Melo, convido você a participar deste estudo que t em como objetivo definir o tipo de cuidado necessário ao s pacientes adultos atendidos na unidade de pronto-socorro deste hospital, para possibilitar o estudo do número de funcionários exigidos para a assistência de en fermagem. Para isso, necessito preencher um questionário que vai mostrar as características para det erminar os cuidados que você precisa receber enquanto estiver neste serviço de saúde. Sua colaboração será a permissão para que eu o u algum aluno treina do observe e anote as suas necessidades de assistência e, caso seja preciso, poderá nos ajudar dizendo se tem a Iguma necessidade relacionada no questionário. Todas as informações fornecid as serão mantidas em segredo e serão utilizad as somente para a pesquisa. S eu nome $n$ ão irá aparecer e, quando terminarmos esta pesquisa, or esultado final poderá ser divulg ado em revistas e/ou apresentado em encontros científ icos. Sua participação é completamente voluntária e não haverá custo por estar participando. Também poderá deixar de participar da pesquisa a qualquer momento, sem que você seja prejudicado por isso. Os resultados dessa pesquisa não tra rão benefícios diretos $p$ ara você neste momento, mas fornecerão informações e trarão benefícios par a ajudar a equipe de enfermagem a melhorar o atendimento no pronto-socorr o. Se tiver alguma dúvida, poderá perguntar o u entrar em contato com o pesquisador pelo telefone e/o u endereço abaixo. Obrigado pela colaboração.

Após ter conhecimento sobre como poderei colaborar com esta pes quisa, concordo em participar, não tendo sofrido nenhuma pressão para tanto.

$\mathrm{Eu}$, (ou responsáve

por_ aceito participar d este trabalh o e sei que, ao fin al, o meu nome será mantido em segredo. Sei, também, que quando eu não quiser mais participar, poderei $\mathrm{p}$ arar. Decla ro que tive a oportunidade de discutir questionário e que re cebi uma cópia dest e documento, assinad a pelo pesquisador responsável.

São Paulo, de de 2009

Renato Ohara - Pesquisador e-mail: renatoeerp@usp.br f:(11)8589-4134

Faculdade Santa Marcelina

Rua Cachoeira Utupanema $n^{\circ} 60$ - 08270-140 Itaquera - Sao Paulo - SP - Brasil

Telefone: 11 2217-9110 
APÊNDICE 5

INSTRUMENTO PARA REGISTRO DE DADOS

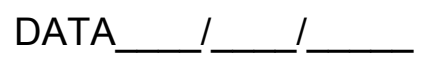

NOME:

Registro:

LEITO/MACA:

SETOR:( )Observação masculina ( )Observação feminina ( ) Emergência

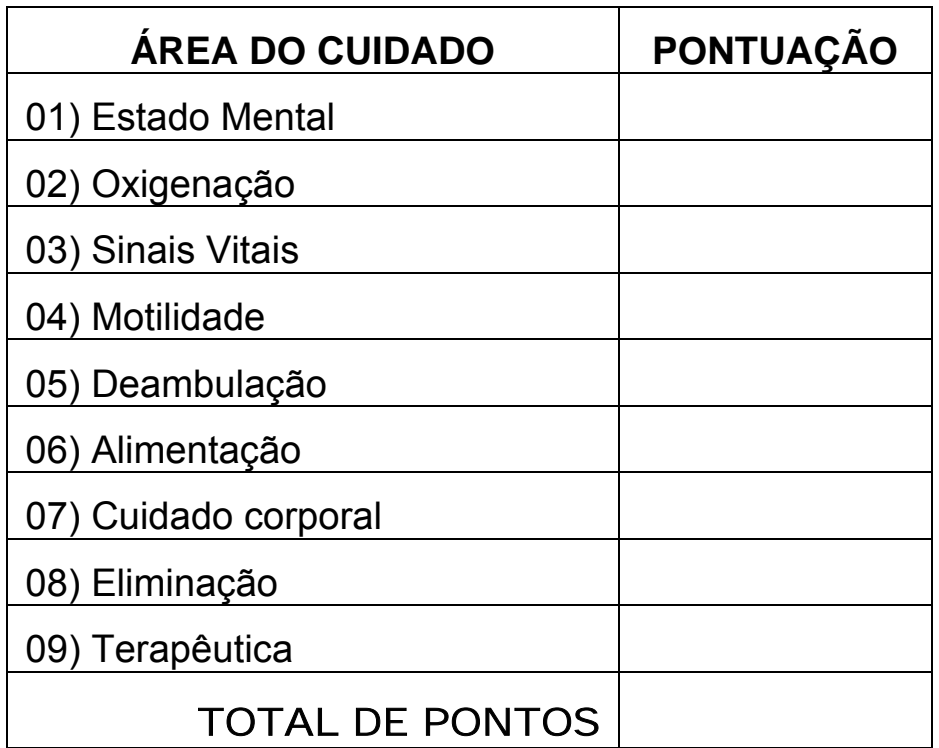


Anexo 
ANEXO 1

Instrumento de Classificação de Pacientes (FUGULIN, 2002)

\begin{tabular}{|c|c|c|c|c|}
\hline \multirow{2}{*}{$\begin{array}{l}\text { ÁREA DE } \\
\text { CUIDADO }\end{array}$} & \multicolumn{4}{|c|}{ GRADAÇÃO DA COMPLEXIDADE ASSISTENCIAL } \\
\hline & 4 & 3 & 2 & 1 \\
\hline Estado Mental & Inconsciente & $\begin{array}{l}\text { Períodos de } \\
\text { inconsciência }\end{array}$ & $\begin{array}{c}\text { Períodos de } \\
\text { desorientação no } \\
\text { tempo e no } \\
\text { espaço }\end{array}$ & $\begin{array}{l}\text { Orientação no } \\
\text { tempo e no } \\
\text { espaço }\end{array}$ \\
\hline Oxigenação & $\begin{array}{l}\text { Ventilação mecânica } \\
\text { (uso do ventilador a } \\
\text { pressão ou a volume) }\end{array}$ & $\begin{array}{l}\text { Uso contínuo de } \\
\text { máscara ou cateter } \\
\text { de oxigênio }\end{array}$ & $\begin{array}{l}\text { Uso intermitente } \\
\text { de máscara ou } \\
\text { cateter de } \\
\text { oxigênio }\end{array}$ & $\begin{array}{l}\text { Não depende de } \\
\text { oxigênio }\end{array}$ \\
\hline Sinais Vitais & $\begin{array}{c}\text { Controle em intervalos } \\
\text { menores ou iguais a } 2 \\
\text { horas }\end{array}$ & $\begin{array}{l}\text { Controle em } \\
\text { intervalos de } 4 \text { horas }\end{array}$ & $\begin{array}{l}\text { Controle em } \\
\text { intervalos de } 6 \\
\text { horas }\end{array}$ & $\begin{array}{c}\text { Controle de } \\
\text { rotina (8 horas) }\end{array}$ \\
\hline Motilidade & $\begin{array}{l}\text { Incapaz de movimentar } \\
\text { qualquer segmento } \\
\text { corporal } \\
\text { Mudança de decúbito e } \\
\text { movimentação passiva } \\
\text { programada e } \\
\text { realizada pela } \\
\text { enfermagem }\end{array}$ & $\begin{array}{c}\text { Dificuldade para } \\
\text { movimentar } \\
\text { segmentos corporais } \\
\text { Mudança de } \\
\text { decúbito e } \\
\text { movimentação } \\
\text { passiva auxiliada } \\
\text { pela enfermagem }\end{array}$ & $\begin{array}{l}\text { Limitação de } \\
\text { movimentos }\end{array}$ & $\begin{array}{l}\text { Movimenta todos } \\
\text { os segmentos } \\
\text { corporais }\end{array}$ \\
\hline Deambulação & Restrito ao leito & $\begin{array}{l}\text { Locomoção através } \\
\text { de cadeira de rodas }\end{array}$ & $\begin{array}{l}\text { Necessita de } \\
\text { auxílio para } \\
\text { deambular }\end{array}$ & Ambulante \\
\hline Alimentação & $\begin{array}{l}\text { Através de cateter } \\
\text { central }\end{array}$ & $\begin{array}{l}\text { Através de sonda } \\
\text { nasogástrica }\end{array}$ & $\begin{array}{l}\text { Por boca com } \\
\text { auxílio }\end{array}$ & Auto-suficiente \\
\hline Cuidado corporal & $\begin{array}{l}\text { Banho no leito, higiene } \\
\text { oral realizada pela } \\
\text { enfermagem }\end{array}$ & $\begin{array}{l}\text { Banho no chuveiro, } \\
\text { higiene oral } \\
\text { realizada pela } \\
\text { enfermagem }\end{array}$ & $\begin{array}{c}\text { Auxílio no banho } \\
\text { de chuveiro e/ou } \\
\text { na higiene oral }\end{array}$ & Auto-suficiente \\
\hline Eliminação & $\begin{array}{l}\text { Evacuação no leito e } \\
\text { uso de sonda vesical } \\
\text { para controle de } \\
\text { diurese }\end{array}$ & $\begin{array}{l}\text { Uso de comadre ou } \\
\text { eliminações no leito }\end{array}$ & $\begin{array}{l}\text { Uso de vaso } \\
\text { sanitário com } \\
\quad \text { auxílio }\end{array}$ & Auto-suficiente \\
\hline Terapêutica & $\begin{array}{c}\text { Uso de drogas } \\
\text { vasoativas para } \\
\text { manutenção de P.A. }\end{array}$ & $\begin{array}{l}\text { E.V. contínua ou } \\
\text { através de sonda } \\
\text { nasogástrica }\end{array}$ & E.V. intermitente & I.M. ou V.O. \\
\hline
\end{tabular}

\begin{tabular}{|c|c|}
\hline Complexidade assistencial & Pontuação \\
\hline Intensivo & Acima de 31 \\
\hline Semi-intensivo & $27-31$ \\
\hline Alta dependência & $21-26$ \\
\hline Intermediário & $15-20$ \\
\hline Mínimo & $9-14$ \\
\hline
\end{tabular}



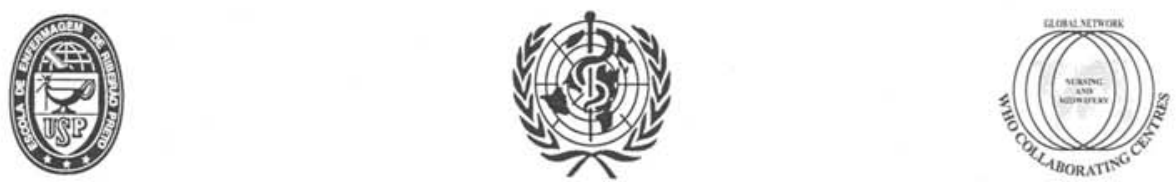

Escola de Enfermagem de Ribeirão Preto - Universidade de São Paulo

Centro Colaborador da Organização Mundial da Saúde para

o Desenvolvimento da Pesquisa em Enfermagem

Avenida Bandeirantes, 3900 - Campus Universitário - Ríbeirão Preto - CEP 14040-902 - São Paulo - Brasil FAX: (55) - 16-3633-3271 / TELEFONE: (55) - 16-3602-3382

\section{COMITÊ DE ÉTICA EM PESQUISA DA EERPIUSP}

Of.CEP-EERP/USP - 274/2008

Ribeirão Preto, 15 de dezembro de 2008

Prezada Senhora,

Comunicamos que o projeto de pesquisa, abaixo especificado, foi analisado e considerado APROVADO AD REFERENDUM pelo Comitê de Ética em Pesquisa da Escola de Enfermagem de Ribeirão Preto da Universidade de São Paulo, em 15 de dezembro de 2008.

Protocolo:

$n^{\circ} 0975 / 2008$

Projeto:

CARACTERIZAÇÃO DO PERFIL ASSISTENCIAL DA CLIENTELA DO PRONTO SOCORRO PARA O DIMENSIONAMENTO DO PESSOAL DE ENFERMAGEM.

Pesquisadores: Márcia Regina Antonietto da Costa Melo Renato Ohara

Em atendimento à Resolução 196/96, deverá ser encaminhado ao CEP o relatório final da pesquisa e a publicação de seus resultados, para acompanhamento, bem como comunicada qualquer intercorrência ou a sua interrupção.

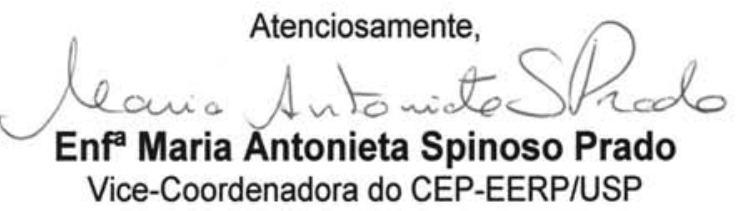

IIma. Sra.

Profa. Dra . Márcia Regina Antonietto da Costa Melo

Departamento de Enfermagem Geral e Especializada

Escola de Enfermagem de Ribeirão Preto - USP 